\title{
The ion-ion recombination coefficient $\alpha$ : Comparison of temperature- and pressure-dependent parameterisations for the troposphere and lower stratosphere
}

Marcel Zauner-Wieczorek ${ }^{1}$, Joachim Curtius ${ }^{1}$, Andreas Kürten ${ }^{1}$

$5 \quad{ }^{1}$ Institute for Atmospheric and Environmental Sciences, Goethe University Frankfurt am Main, Frankfurt am Main, 60629, Germany

Correspondence to: Marcel Zauner-Wieczorek (zauner-wieczorek@iau.uni-frankfurt.de) and Andreas Kürten (kuerten@iau.uni-frankfurt.de) 
10 Abstract. Many different atmospheric, physical and chemical processes are affected by ions. An important sink for atmospheric ions is the reaction and mutual neutralisation of a positive and negative ion, also called ion-ion recombination. While the value for the ion-ion recombination coefficient $\alpha$ is well-known for standard conditions (namely $1.7 \cdot 10^{-6} \mathrm{~cm}^{3} \mathrm{~s}^{-1}$ ), it needs to be calculated for deviating temperature and pressure conditions, especially for applications at higher altitudes of the atmosphere. In this work, we review the history of theories and parameterisations of the ion-ion recombination coefficient,

15 focussing on the temperature and pressure dependencies and on the altitude range of between 0 and $20 \mathrm{~km}$. Commencing with theories based on J. J. Thomson's work, we describe important semi-empirical adjustments as well as field, model and laboratory data sets, followed by a short review of physical theories that take the microscopic processes during recombination into account, including a molecular dynamics approach. We present a comparison between all theories, parameterisations, field, model, and laboratory data sets to conclude on a favourable parameterisation. While many theories agree well with field data above approximately $10 \mathrm{~km}$ altitude, the nature of the recombination coefficient is still widely unknown between Earth's surface and an altitude of $10 \mathrm{~km}$. According to the current state of knowledge, it appears most reasonable to assume a constant value for the recombination coefficient for this region, while we recommend using a parameterisation for altitudes above $10 \mathrm{~km}$. Overall, the parameterisation of Brasseur and Chatel (1983) shows the most convincing results. The need for future research, be it in the laboratory or by means of modelling, is identified.

\section{Introduction}

Earth's atmosphere is not only a neutral mixture of gases, but also contains gas-phase ions that are crucial to the phenomena of atmospheric electricity. They play a central role in meteorological processes in thunderstorms (Sagalyn et al., 1985), maintaining the global atmospheric electrical circuit (Harrison, 2004), the formation of aerosol particles with the ion-induced nucleation mechanism (Hirsikko et al., 2011), and the propagation of radio waves in the ionosphere (Basu et al., 1985), to name but a few processes. It is, therefore, important to understand the production and loss of atmospheric ions. There are several sources of ions in the atmosphere, of which ionisation by galactic cosmic rays (GCRs) is the most important (Bazilevskaya et al., 2008). Close to the ground, ionisation by the radioactive decay of radon as well as lightning are further sources of atmospheric ions (Viggiano and Arnold, 1995). Further, minor sources of ionisation in the atmosphere include solar cosmic rays (also called solar energetic particles, SEPs) and magnetospheric electrons (Bazilevskaya et al., 2008). The two important sinks for atmospheric ions are the reaction of a positive ion and negative ion, the so-called recombination, as well as the condensation of ions onto aerosol particles (Viggiano and Arnold, 1995). The ion-ion recombination coefficient $\alpha$ describes the reaction rate of the recombination of a positive and negative ion in the gas phase; its unit is $\mathrm{cm}^{3} \mathrm{~s}^{-1}$, which is used throughout this work unless noted otherwise.

In this work, we summarise the history and fundamentals of the theory behind ion-ion recombination in Sect. 2, followed by a

40 description of empirical adjustments to the theory in Sect. 3. We focus on the applicability of the theory to atmospheric conditions, especially for the troposphere and lower stratosphere, i.e. in an altitude range of 0 to $20 \mathrm{~km}$. In Sect. 4, we highlight 
the most important advancements with respect to limiting sphere theories and describe their potential for the determination of the ion-ion recombination. We compare the available parameterisations and theories with field data, laboratory data and a model simulation for this range in Sect. 5 , to conclude, finally, on the best parameterisation available today and to identify the demand for future research in Sect. 6 .

\section{The fundamental theories}

The theoretical foundation of the recombination of gaseous ions was laid down by J. J. Thomson and Ernest Rutherford. The theory based on their approach is referred to as Thomson theory in the literature. In their work "On the Passage of Electricity of Gases exposed to Röntgen Rays", Thomson and Rutherford (1896) discuss, for the first time, the sources and sinks of ions in the gas phase. In their experimental setup, the source of ions are X-rays while the sinks are the recombination of negative and positive ions as well as losses to the electrodes. They describe the temporal change of the number concentration of ions $n$ according to Eq. (1):

$\frac{\mathrm{d} n}{\mathrm{~d} t}=q-\alpha n^{2}-L$

where $q$ is the ion production rate, $\alpha$ is the ion-ion recombination coefficient, and $L$ is the loss rate to the electrodes. This formula already includes the assumption that the number concentrations of negative and positive ions, $n_{-}$and $n_{+}$, are about equal and, therefore, the product $n \_n_{+}$can be simplified to $n^{2}$. They conclude that when the electrode current is small $(L \approx 0)$ and the system is in a steady state $(\mathrm{d} n / \mathrm{d} t=0)$, the number concentration of gas-phase ions can be calculated in a simple way (Eq. (2)):

$n^{2}=\frac{q}{\alpha}$.

60 As per today's convention, $q$ is the production rate for ion pairs so that $n$ in Eq. (1) and (2) must be specified to be either $n_{+}$or $n_{-}$, not to be confused with $n_{\text {total }}=n_{+}+n_{-}$. Equation (2) can be rearranged to determine $\alpha$ when the ion pair production rate and the number concentration of positive or negative ions are known. A few years later, in 1906, the Nobel Prize in Physics was awarded to J. J. Thomson for his studies on the electrical conductivity of gases.

Soon after Thomson and Rutherford's publication, several experiments to determine the ion-ion recombination coefficient

65 were pursued by different scientists. It was shown that $\alpha$ is dependent on the chemical composition of the surrounding gas, as well as on the temperature and pressure. Here, we focus on experiments in air. Many of these first approaches have been reviewed by Lenz (1932), who himself had developed a sophisticated experimental setup in order to control losses due to diffusion and deposition on walls. It is remarkable that even during this time, the determined values of $\alpha$ are similar to the one used today and have not changed significantly since then. For standard conditions, i.e. $0^{\circ} \mathrm{C}$ and $1013 \mathrm{hPa}$, Thirkill (1913)

70 determined a value of $1.7 \cdot 10^{-6} \mathrm{~cm}^{3} \mathrm{~s}^{-1}$, while Thomson (1924) determined a value of $2.0 \cdot 10^{-6} \mathrm{~cm}^{3} \mathrm{~s}^{-1}$. Lenz (1932) reported $(1.7 \pm 0.1) \cdot 10^{-6} \mathrm{~cm}^{3} \mathrm{~s}^{-1}$ for the conditions of $18^{\circ} \mathrm{C}$ and $1013 \mathrm{hPa}$. The value for $\alpha$ used nowadays is $1.6 \cdot 10^{-6} \mathrm{~cm}^{3} \mathrm{~s}^{-1}(\mathrm{e} . \mathrm{g}$. Franchin et al., 2015) and is taken from Israël (1971) (which is the English translation of the first edition in German: Israël 
(1957)). In addition, Gardner (1938) reported the value of $2.1 \cdot 10^{-6} \mathrm{~cm}^{3} \mathrm{~s}^{-1}$ for pure oxygen, $1013 \mathrm{hPa}$ and $25^{\circ} \mathrm{C}$. Sayers (1938) reported a value of $2.3 \cdot 10^{-6} \mathrm{~cm}^{3} \mathrm{~s}^{-1}$, while Nolan (1943), who has also reviewed previous works, concluded on

$751.4 \cdot 10^{-6} \mathrm{~cm}^{3} \mathrm{~s}^{-1}$. Within a particular uncertainty range, these values do agree quite well and no further ado appears to be necessary to discuss this value. However, the values for $\alpha$ differ tremendously when temperatures are lower than $0{ }^{\circ} \mathrm{C}$ and pressures are lower than $1013 \mathrm{hPa}$, as Lenz (1932) has already shown. Nevertheless, a correct value for $\alpha$ is crucial for the analysis of field data and for the calculations of atmospheric models at higher altitudes in the atmosphere where temperatures and pressures are different from ground level. This calls for a good understanding of the mechanisms involved in ion-ion recombination and a solid parameterisation of $\alpha$.

In a later work, Thomson (1924) explains his theory in more detail and provides a kinetic derivation of the recombination coefficient. In his approach, recombination occurs when the two oppositely charged ions collide with a neutral molecule of the surrounding gas within a certain sphere $d$ around the ions. This sphere will be subject to a more detailed discussion in Sect. 4 . Here, it is defined as the sphere in which the ions of opposite signs experience Coulomb attraction (Loeb, 1960). Thomson 85 deduced that $\alpha$ is dependent on the average speeds of the two ions, $v_{+}$and $v_{-}$, respectively, according to Eq. (3) for low pressures and Eq. (4) for high pressures:

$\alpha=2 \pi \cdot\left(v_{+}{ }^{2}+v_{-}{ }^{2}\right)^{0.5} \cdot d^{3} \cdot\left(\frac{1}{\lambda_{+}}+\frac{1}{\lambda_{-}}\right)$,

where the pressure is low, i.e. $d \lambda^{-1}$ is small, and where $\lambda_{+}$and $\lambda_{-}$are the mean free paths of the positive and negative ions, respectively. $d$ is the radius of the (equally large) spheres around each of the ions, in which the collision occurs. This will be discussed later.

$\alpha=2 \pi \cdot\left(v_{+}{ }^{2}+v_{-}{ }^{2}\right)^{0.5} \cdot d^{2}$,

where the pressure is high, i.e. $d \lambda^{-1}$ is large. From these equations, Thomson (1924) deduced that the recombination coefficient is proportional to the pressure for low pressures (because of the sum of the reciprocal mean free paths of the ions), whereas it is independent of the pressure for high pressures. This was supported by the measurements of Thirkill (1913) who found $\alpha$ to

95 be proportional to the pressure throughout the measurement range of approximately 200 to $1000 \mathrm{hPa}$. Thus, the pressure regime of $1013 \mathrm{hPa}$ and below is included in the low-pressure scenario. The transition pressure from the low-pressure to the highpressure regime is clearly above $1013 \mathrm{hPa}$ and, thus, beyond the concern of atmospheric application. The temperature dependence is given as $\alpha \sim T^{-2.5}$ for low pressures and $\alpha \sim T^{-1.5}$ for high pressures because $d \sim T^{-1}$ and $v_{+,-} \sim T^{0.5}$ (Thomson, 1924). Hence, the recombination coefficient decreases with rising temperature for pressures below $1013 \mathrm{hPa}$. For the 100 troposphere, this leads to a somewhat counterbalancing effect on $\alpha$ for increasing altitudes when both the temperature and the pressure drop simultaneously.

Another approach to explain the recombination of ions was introduced by Langevin (1903a, 1903b) whose ansatz is based on the speeds of ions in an electrical field, as opposed to the thermodynamic approach of Thomson. To account for the 
effectiveness of collisions of a negative and positive ion with regard to recombination, Langevin introduced the ratio of successful recombinations per collision, $\varepsilon_{\mathrm{L}}$, which is included in the formula proposed by him to determine $\alpha$ (Eq. (5)):

$\alpha=4 \pi \cdot\left(\mu_{+}+\mu_{-}\right) \cdot \varepsilon_{\mathrm{L}}$,

where $\mu_{+}$and $\mu_{-}$are the ion mobilities of the positive and negative ions, respectively, defined by Eq. (6a) and (6b):

$v_{+}=\mu_{+} \cdot\left(E+\frac{e}{r^{2}}\right)$,

$v_{-}=-\mu_{-} \cdot\left(E+\frac{e}{r^{2}}\right)$,

110 where $v_{+}$and $v_{-}$are the speeds of the positive and negative ions, respectively, $E$ is the external electrical field, and $e \cdot r^{-2}$ is the electrical field produced by the ions. Here, $e$ is the elementary charge and $r$ is the distance between the two ions of opposite charge (Langevin, 1903a). The consideration of the recombination efficiency leads to an adapted term for the recombination sink (Langevin, 1903a), shown in Eq. (7):

$\frac{\mathrm{d} n_{ \pm}}{\mathrm{d} t}=-4 \pi \cdot\left(\mu_{+}+\mu_{-}\right) \cdot \varepsilon_{\mathrm{L}} \cdot n_{+} \cdot n_{-}$.

115 Langevin (1903b) further determined the pressure dependence of $\varepsilon_{\mathrm{L}}$ (and, thus, of $\alpha$ ). For $1013 \mathrm{hPa}, \varepsilon_{\mathrm{L}}=0.27$ and $\varepsilon_{\mathrm{L}} \sim p^{2}$ (and, thus, $\alpha \sim p^{2}$ ) for pressures below $1013 \mathrm{hPa}$. This, however, is in contradiction to Thomson (1924) who stated that $\alpha \sim p$ for low pressures. Loeb and his colleagues later argued that the assumptions made by Langevin to calculate $\varepsilon_{\mathrm{L}}$ are based on incorrect, sometimes even antithetical assumptions. They even stated that this correction factor was only introduced to make the experimental results fit the theoretical ones. The application of Langevin theory is only considered valid for very high pressures (above approximately $10 \mathrm{~atm}$ ) (Loeb and Marshall, 1929; Gardner, 1938; Loeb, 1960) and is, thus, not within the focus of this work.

Loeb and Marshall (1929) greatly advanced and refined the Thomson theory. They introduced the concept of a ternary, or three-body, recombination (without calling it this way). This means that the collision of the two ions of opposite sign needs a neutral collision partner to dissipate excess energy. This mechanism is opposed to the two-body, or binary, recombination where two ions recombine upon collision without energy dissipation by a third body. Loeb and Marshall (1929) introduce a probability term, similar to Langevin, for collisions leading to recombination, extending Eq. (4) to a more refined Eq. (8):

$\alpha=\pi \cdot d^{2} \cdot\left(U_{+}{ }^{2}+U_{-}{ }^{2}\right)^{0.5} \cdot\left[1-\frac{\lambda^{2}}{2 d^{2}} \cdot\left(1-\mathrm{e}^{-2 d / \lambda} \cdot\left(\frac{2 d}{\lambda}+1\right)\right)\right]^{2}$,

where the ratio $2 d \cdot \lambda^{-1}$ is defined as $x$. With a number of assumptions and simplifications, and together with validation from experimental work, Gardner (1938) summarised the previous findings and advanced them to a set of equations (Eq. (9) to (12)) that contain macroscopic quantities that are more accessible for direct observation:

$\alpha=1.9 \cdot 10^{-5} \cdot\left(\frac{273}{T}\right)^{1.5} \cdot\left(\frac{1}{M}\right)^{0.5} \cdot \varepsilon_{\mathrm{T}}$, where

$\varepsilon_{\mathrm{T}}=2 w-w^{2}$,

$w=1-2 \cdot \frac{\left[1-e^{-x^{\prime}} \cdot\left(x^{\prime}+1\right)\right]}{x^{\prime 2}}$, and 
$x^{\prime}=0.810 \cdot\left(\frac{273}{T}\right)^{2} \cdot\left(\frac{p}{760}\right) \cdot \frac{\lambda_{\mathrm{air}}}{\lambda}$,

135 where $T$ is the temperature in $\mathrm{K}, M$ is the molecular mass in amu, $\varepsilon_{\mathrm{T}}$ is the recombination probability upon collision, $p$ is the pressure in Torr, $\lambda_{\text {air }}$ is the mean free path of the surrounding air, $\lambda$ is the mean free path of the ions, and the ratio $\lambda_{\text {air }} \cdot \lambda^{-1}=5$. Here, $x$ is not defined by the ratio of $d$ and $\lambda$ anymore, but by $T, p$, and the ratio $\lambda_{\text {air }} \cdot \lambda^{-1}$, and is therefore denoted as $x$. Importantly, Loeb and Marshall (1929) also discuss the limitations of their approach. Firstly, the exact masses of the ions are unknown, as clustered ions and ions from impurities in the sample gas can also occur. This has a non-negligible effect on the

140 value of the recombination coefficient. They argue that this circumstance could be the reason for the variation of results between different authors. Apart from the difference in ion mass, the property of free electron pairs in the surrounding gas may also influence the recombination (Loeb and Marshall, 1929). Secondly, based on the observation that at low temperatures, the measured $\alpha$ value is much smaller than the calculated one, they discuss whether the presumed power of -1.5 for the $T$ dependence might be overestimated.

145 Table 1: Selection of ion-ion recombination theories described in detail by Loeb (1960).

\begin{tabular}{lllll}
\hline Theory & Pressure range & Conditions & $\begin{array}{l}p \text { and } T \\
\text { dependence }\end{array}$ & Description \\
\hline $\begin{array}{llll}\text { Langevin } \\
\text { Langevin-Harper }\end{array}$ & $\begin{array}{l}100 \text { to } 20 \mathrm{~atm} \\
20 \text { to } 2 \mathrm{~atm}\end{array}$ & $\begin{array}{l}d>r_{0}>\lambda \\
r_{0}>d>\lambda\end{array}$ & $p^{-1}$, no $T$ dep. & both ions inside $d$, no diffusive approach \\
Thomson & 1013 to $0.01 \mathrm{hPa}$ & $r_{0}>d \approx \lambda$ & $p^{-0.5}, T^{-1.5}$ & diffusion towards $d$, collision inside $d$ certain \\
Collision cross & $<0.01 \mathrm{hPa}$ & $\lambda>r_{0}>d$ & no $p$ dep., $T^{-0.5}$ & $\begin{array}{l}\text { collision probability } \varepsilon \approx 0, \text { collision driven by } \\
\text { cross section (ionosphere) }\end{array}$ \\
section & & & &
\end{tabular}

A detailed overview of the different theories and their experimental validations can be found in Loeb (1960) (second edition of Loeb (1955)) where he discusses ion-electron and ion-ion recombination. For the latter, cases of $\alpha$ particle- or X-ray-induced ion production are also described that feature a non-uniform spatial ion distribution. Until the beginning of the 1980s, it was

150 hypothesised that, in general, ions are not uniformly distributed in the atmosphere, because the ions are produced along the GCR paths and diffusion may not be sufficiently fast. Bates (1982) showed that ions are mixed sufficiently rapidly in the atmosphere so that the assumption of a uniform ion concentration of the "volume recombination" theories, described in the following, is valid. In Table 1, a selection of recombination theories discussed in detail by Loeb is given. Above atmospheric pressure, Langevin theory is applied. Loeb subclassifies it, firstly, to the range of 20 to 100 atm where there is no diffusional

155 approach of the ions towards each other because they are already within the Coulomb attractive radius $d$ and, secondly, to the range of 2 to 20 atm (called Langevin-Harper theory), where the initial distance of the ions $r_{0}$ is greater than $d$ and so they first have to diffuse towards each other. The subsequent collision inside $d$ is almost certain because of the high pressure. For the pressure range of 0.01 to $1013 \mathrm{hPa}$, i.e. for the lower and middle atmosphere, Thomson theory is applicable. Here, the initial 
distance of the ions is greater than $d$ and the mean free path $\lambda$, therefore a random diffusive approach is necessary. Within $d$, the collision probability $\varepsilon$ is less than 1 . Below $0.01 \mathrm{hPa}$, i.e. in the ionosphere, the collision probability becomes almost 0 and, thus, the collision is then governed by the collision cross section. For super-atmospheric pressures (i.e. in the Langevin regime), $\alpha$ is dependent on $p^{-1}$ and almost independent of $T$ (for $p=$ const.). In the Thomson regime (i.e. from 1013 to $0.01 \mathrm{hPa}$ ), $\alpha$ is dependent on $p^{-0.5}$ and $T^{-1.5}$, while in the cross section regime (i.e. $<0.01 \mathrm{hPa}$ ), it is independent of the pressure and dependent on $T^{-0.5}$. The radius $d$ is derived from equalising the Coulomb potential energy $\left(e^{2} d^{-1}\right)$ and the thermal energy of motion of the surrounding molecules and ions in the absence of an electrical field, $1.5 k_{\mathrm{B}} T$ (Loeb, 1960), as shown in Eq. (13):

$d=\frac{e^{2}}{1.5 \cdot k_{\mathrm{B}} T}$.

Loeb (1960) stresses that the pre-factor value of 1.5 for the thermal energy is debated, ranging from 1 (Tamadate et al., 2020), 1.5 (Thomson, 1924), and 2.4 (Natanson, 1959a) to 6 (Loeb and Marshall, 1929), amongst others. Loeb and Marshall (1929) approximate the radius $d$ to be in the order of $10 \mathrm{~nm}$ when the value of $6 k_{\mathrm{B}} T$ is used for the thermal energy. Thus, a rough estimate of 10 to $60 \mathrm{~nm}$ for $d$ can be derived from different Thomsonian theories.

A detailed derivation of all theories and the above mentioned equations is given within Loeb (1960). In his work, the only variation in the Thomson parameterisation for $\alpha$ from the one presented by Gardner (1938) is the first factor in the formula for the recombination coefficient, as shown in Eq. (14):

$\alpha=1.73 \cdot 10^{-5} \cdot\left(\frac{273}{T}\right)^{1.5} \cdot\left(\frac{1}{M}\right)^{0.5} \cdot \varepsilon_{\mathrm{T}}$.

175 Israël (1957) has further altered this parameterisation. He also included the few experimental data available at that time into his parameterisation. In the derivation of the formula, he used the normal value of $1.6 \cdot 10^{-6} \mathrm{~cm}^{3} \mathrm{~s}^{-1}$ for $\alpha$, however, he did not include a reference for this. Furthermore, he stated that the recombination of small negative and small positive ions are accompanied by the recombination of small and big ions and, also, of small ions with neutrals, so that a whole equation system of recombination rates would result. He proposed the slightly altered parameterisation of the small ion recombination according

to Eq. (15):

$\alpha=1.95 \cdot 10^{-6} \cdot\left(\frac{273}{T}\right)^{1.5} \cdot f\left(x^{\prime}\right)$, where

$f\left(x^{\prime}\right)=1-\frac{4}{x^{\prime 2}} \cdot\left[1-e^{-x^{\prime}} \cdot\left(x^{\prime}+1\right)\right]^{2}$,

where $x^{\prime}$ is given in Eq. (12) and $\lambda_{\text {air }} \cdot \lambda^{-1} \approx 3$ for air. The molecular mass is not included anymore. Note that Gardner (1938) and Loeb (1960) used the value of 5 for $\lambda_{\text {air }} \cdot \lambda^{-1}$.

185 In the course of time, additional sinks for atmospheric ions, other than the ion-ion recombination process, have been discussed. Lenz (1932) explained the strong deviations observed between several experimentally derived values for $\alpha$ by the authors' negligence of losses due to their experimental setups, for example, by wall losses. In addition, the attachment of ions to aerosol particles suspended in the surrounding gas has been found to cause problems in the quantification of $\alpha$, especially in field studies performed in the atmosphere (Rosen and Hofmann, 1981; Morita, 1983), while Franchin et al. (2015), who conducted 

recombination experienced more advances in the decades following Loeb, Gardner and Israël, as discussed in the next section.

\section{Empirical adjustments to Thomson theory}

The next important theoretical step in order to understand and predict the ion-ion recombination was to investigate further the different influences of binary and ternary collisions on the recombination coefficient. Smith and Church (1977) determined the recombination rates of $\mathrm{NO}^{+}$and $\mathrm{NO}_{2}^{-}$in an experimental setup for different temperatures and pressures typical for the atmosphere. They inferred the binary $\left(\alpha_{2}\right)$ and ternary $\left(\alpha_{3}\right)$ recombination rates for different altitudes. They found that above $30 \mathrm{~km}$, where air is less dense, the binary recombination is dominant, while below $30 \mathrm{~km}$, where air is denser and three-body collisions become more likely, the ternary recombination is more important. For ground level, they determined a rather high value of $\alpha_{3}=3 \cdot 10^{-6} \mathrm{~cm}^{3} \mathrm{~s}^{-1}$. Interestingly, the total ion-ion recombination rate is almost constant throughout the whole troposphere according to their work. Only above $10 \mathrm{~km}$, does the value decrease until an altitude of about $50 \mathrm{~km}$. With regard to the temperature, they determined a dependency of $T^{-0.4}$ from their data for binary recombination. For the ternary recombination, they expected a dependency of $T^{-2.5}$ to $T^{-3}$, while Fisk et al. (1967) even determined $T^{-4.1}$ in a recombination experiment with $\mathrm{Tl}_{2} \mathrm{I}^{+}$and $\mathrm{TlI}_{2}{ }^{-}$. Smith and Church (1977) have inferred an equation for the binary recombination from further experiments (Eq. (17)), which was later adapted by Bates (1982) (Eq. (18)):

$\alpha_{2}=6.8 \cdot 10^{-7} \cdot T^{-0.4}$ and

$\alpha_{2}=5 \cdot 10^{-8} \cdot\left(\frac{300}{T}\right)^{0.5}$,

where $T$ is in K. Furthermore, Smith and Adams (1982) presented a parameterisation valid for the altitude range of 10 to $60 \mathrm{~km}$; this is simple because it only depends on the altitude, as Eq. (19) shows:

$\alpha=1.63 \cdot 10^{-5} \cdot e^{-\frac{h}{7.38}}+5.25 \cdot 10^{-8}$,

210 where $h$ is the altitude in $\mathrm{km}$. The two terms of Eq. (19) represent the ternary and binary recombination, respectively. Bates (1982) criticised that the binary and ternary recombination rates had been erroneously considered additive in previous works, stating that both processes are not independent of each other. Instead of the binary recombination rate $\alpha_{2}$, he defined the enhancement due to the binary channel, $\Delta \alpha_{2}$, and calculated $\alpha_{3}, \Delta \alpha_{2}$, and the resulting total recombination coefficient, $\alpha_{\mathrm{T}}$, in a Monte Carlo simulation for altitudes between 0 and $40 \mathrm{~km}$. Interestingly, Smith, Church, Adams and Bates have never 215 cited the works of Israël (1957) or Lenz (1932). It seems that the two latter authors have been overseen, probably because they published their works in German (however, Israël's textbook was translated into English in 1971). This is especially remarkable as Bates (1982) determined $\alpha_{\mathrm{T}}$ to be $1.67 \cdot 10^{-6} \mathrm{~cm}^{3} \mathrm{~s}^{-1}$ at ground level which is in striking agreement with Israël (1957) $\left(1.6 \cdot 10^{-6} \mathrm{~cm}^{3} \mathrm{~s}^{-1}\right)$ and Lenz (1932) $\left((1.7 \pm 0.1) \cdot 10^{-6} \mathrm{~cm}^{3} \mathrm{~s}^{-1}\right)$. Instead, Bates referred to Sayers (1938) $\left(2.3 \cdot 10^{-6} \mathrm{~cm}^{3} \mathrm{~s}^{-1}\right)$ and Nolan (1943) $\left(1.4 \cdot 10^{-6} \mathrm{~cm}^{3} \mathrm{~s}^{-1}\right)$ whom he thought to be the first experimenters to quantitatively and accurately determine $\alpha$. 
By that time, science was in urgent need of correct and altitude-resolved values for the recombination coefficient. Arnold and Fabian (1980) presented a method to calculate the concentration of gaseous sulfuric acid from measured concentration ratios of the ambient $\mathrm{HSO}_{4}{ }^{-}$and $\mathrm{NO}_{3}{ }^{-}$ions. The recombination coefficient, which describes the sink for ions, forms part of the formula (see Arnold and Qiu (1984) for a more detailed derivation). Until the early 1980s, this method was the only way to determine the concentration of trace gases, such as sulfuric or nitric acid, in the different layers of the atmosphere.

The need for an experimental investigation in the atmosphere was answered by Gringel et al. (1978), Rosen and Hofmann (1981), and Morita (1983). Gringel et al. (1978) conducted balloon-borne measurements of the air conductivity and the ionisation rate $q$. They reported a recombination coefficient of $1.4 \cdot 10^{-6} \mathrm{~cm}^{3} \mathrm{~s}^{-1}$ at ground level and $4 \cdot 10^{-7} \mathrm{~cm}^{3} \mathrm{~s}^{-1}$ at $25 \mathrm{~km}$ altitude. Rosen and Hofmann (1981) and Morita (1983), on the other hand, measured the positive ion number concentration $n_{+}$ directly along with the ionisation rate $q$. Thus, Rosen and Hofmann's data, being available earlier than Morita's, were considered to be the most reliable ones at that time because they measured the relevant parameters simultaneously (Arijs, 1983). Applying Eq. (2), they calculated $\alpha$ for different altitude levels. The derived data points followed a profile suggested by theory that accounted for both binary and ternary recombination. However, below $9 \mathrm{~km}$ the derived values for the ion-ion recombination were unexpectedly large. As the authors themselves wrote, in the troposphere, the losses of ions due to aerosol particle attachment have to be taken into account, otherwise the loss due to ion-ion recombination is overestimated when using 235 Eq. (2); this is why only the values above $9 \mathrm{~km}$ are reliable. Nevertheless, these measurements have led to further adjustments of the parameterisations, such as the ones by Arijs et al. (1983) and Brasseur and Chatel (1983). Arijs et al. (1983) presented a formula that contains two terms, accounting for binary and ternary reactions, as shown in Eq. (20):

$\alpha=6 \cdot 10^{-8} \cdot\left(\frac{300}{T}\right)^{0.5}+1.25 \cdot 10^{-25} \cdot[\mathrm{M}] \cdot\left(\frac{300}{T}\right)^{4}$,

where $T$ is in $\mathrm{K}$ and $[\mathrm{M}]$ is the number density of air molecules (representing the pressure dependence), given by Eq. (21a):

$[\mathrm{M}]=9.656 \cdot 10^{18} \cdot\left(\frac{p}{T}\right)$

where $[\mathrm{M}]$ is in $\mathrm{cm}^{-3}, p$ is in Torr, and $T$ is in K. It can be converted to Eq. (21b) when the pressure unit of hPa is used instead: $[\mathrm{M}]=7.243 \cdot 10^{18} \cdot\left(\frac{p}{T}\right)$.

Independently, Brasseur and Chatel (1983) proposed a very similar formula that only differs in the factor of the ternary recombination term (Eq. (22)):

$245 \alpha=6 \cdot 10^{-8} \cdot\left(\frac{300}{T}\right)^{0.5}+6 \cdot 10^{-26} \cdot[\mathrm{M}] \cdot\left(\frac{300}{T}\right)^{4}$.

Due to the $T^{-1}$ dependence of [M], the ternary recombination coefficient ultimately shows a $T^{-5}$ dependence in Arijs et al. (1983) and Brasseur and Chatel (1983), which is even stronger than previously discussed.

In the same year, Morita (1983) conducted measurements comparable to Rosen and Hofmann's. Morita also found reasonable results for altitudes above $6 \mathrm{~km}$ and a strong disagreement of the observed results from the theoretically expected ones below $2506 \mathrm{~km}$ for the above-mentioned reason. Bates (1985) synthesised his earlier model results and the measurements by Morita to define another parameterisation that is merely dependent on the altitude, as shown in Eq. (23): 
$\alpha=5.33 \cdot 10^{-6} \cdot e^{-0.111 \cdot h}$,

where $h$ is the altitude in $\mathrm{km}$ and which is valid for the range of 10 to $25 \mathrm{~km}$. Below $10 \mathrm{~km}, \alpha$ is expected to be constant at $1.7 \cdot 10^{-6} \mathrm{~cm}^{3} \mathrm{~s}^{-1}$.

In parallel, Hickman (1979) developed another approach to determine $\alpha$. Based on a complex potential model, the neutralisation of two ions of opposite sign is determined by an electron transfer from the negative to the positive ion, taking into account internal electron excitation changes. In the semi-empirical Eq. (24), $\alpha$ depends on the temperature $T$, the reduced mass $m$ and the electron affinity $E A$ of the negative ion, i.e. its electron detachment energy:

$\alpha=2.28 \cdot 10^{-5} \cdot\left(\frac{T}{300}\right)^{-0.5} \cdot m^{-0.5} \cdot E A^{-0.4}$

where $T$ is in K, $m$ is in amu, and $E A$ is in eV. Miller (1980), however, cites Hickman (1979) with an adapted formula (Eq. (25)) for $T \leq 1000 \mathrm{~K}$ :

$\alpha=5.33 \cdot 10^{-7} \cdot\left(\frac{T}{300}\right)^{-0.5} \cdot m^{-0.5} \cdot E A^{-0.4}$.

Due to the mass and electron affinity dependencies, the recombination coefficient can vary by an order of magnitude or more, e.g. from $(49 \pm 20) \cdot 10^{-6} \mathrm{~cm}^{3} \mathrm{~s}^{-1}$ for $\mathrm{NO}^{+}+\mathrm{O}^{-}$to $(4.1 \pm 0.4) \cdot 10^{-6} \mathrm{~cm}^{3} \mathrm{~s}^{-1}$ for $\mathrm{CClF}_{2}^{+}+\mathrm{Cl}^{-}($Hickman, 1979). The temperature dependence of $T^{-0.5}$ is in agreement with the binary mechanisms of Smith and Adams (1982), Arijs et al. (1983), and Brasseur and Chatel (1983), while the mass dependence of $m^{-0.5}$ is in accordance to Gardner (1938) and Loeb (1960). The dependence on the electron affinity is unique compared to the other approaches. More recently, Miller et al. (2007) have taken on this approach and conducted further experiments. They state, however, that the amount of data is insufficient to stringently prove the equation or improve the exponents.

270 More recently, Franchin et al. (2015) reported experimental data for the recombination coefficient for atmospheric conditions. They have examined the dependency of $\alpha$ on the temperature, relative humidity $R H$, and the number concentrations of sulfur dioxide, $\left[\mathrm{SO}_{2}\right]$, and ozone, $\left[\mathrm{O}_{3}\right]$, in a series of chamber experiments. Their experimental setup did not allow for pressures below $1013 \mathrm{hPa}$, therefore, it is not directly possible to derive new insights with regard to processes in the upper troposphere or stratosphere. However, they did show that $\alpha$ is dependent on $R H$; with increasing relative humidity, the recombination coefficient decreases. At $70 \% R H, \alpha$ is $2.0 \cdot 10^{-6} \mathrm{~cm}^{3} \mathrm{~s}^{-1}$ which is within the known range of uncertainty; however, for $7 \%$ $R H$, it is as high as $8.1 \cdot 10^{-6} \mathrm{~cm}^{3} \mathrm{~s}^{-1}$ (both at $20^{\circ} \mathrm{C}$ ). They convincingly explain this by an increase in ion sizes with increasing $R H$. With a higher humidity, more water ligands are added to the ion cluster and, thus, its size and mass increases while its mobility decreases. This effect could not be reproduced quantitatively by any theory (Franchin et al., 2015). Their data also revealed the temperature dependence of $\alpha$ : at $20^{\circ} \mathrm{C}$, the value was $(2.3 \pm 0.7) \cdot 10^{-6} \mathrm{~cm}^{3} \mathrm{~s}^{-1}$ and, at $-55^{\circ} \mathrm{C}$, it was $(9.7 \pm 1.2) \cdot 10^{-6} \mathrm{~cm}^{3} \mathrm{~s}^{-1}$ (both at $40 \% R H$ ). Unfortunately, the standard deviations of the data points are large, thus, any temperature dependence derived from the four data tuples is inaccurate in itself. Nevertheless, we derived a temperature dependence of $T^{-3}$ from their data. This is in a similar order of magnitude to the findings of Smith and Church (1977) ( $T^{-2.5}$ to $T^{-3}$ ) and is still comparable to Arijs et al. (1983) and Brasseur and Chatel (1983) (both teams: $T^{-5}$ ) for the ternary recombination, 
considering that ternary recombination is the predominant process at atmospheric pressure. Besides this, the recombination coefficient was found to be independent of $\left[\mathrm{O}_{3}\right]$ and $\left[\mathrm{SO}_{2}\right]$.

Since 1985, several physicochemical laboratory experiments have been conducted to shed light on the mystery of the recombination processes; this will be discussed in the next section. However, further improvements of the parameterisation for direct application in the atmosphere have not been made thereafter. One reason could be that the need for this value has become less urgent, since, from that year, trace gases could be measured directly in their neutral forms (Arnold and Hauck, 1985). In addition, most of the parameterisations were in good accordance for the altitude range of 10 to $40 \mathrm{~km}$ (Arijs, 1983) so that no further improvement appeared to be necessary. As yet, for the troposphere, experimental validation of the parameterisations remains open until this day. The best estimate available is the assumption that $\alpha$ remains constant between 0 and $10 \mathrm{~km}$ due to the cancellation of the opposing temperature and pressure effects.

\section{Limiting sphere theories}

As shown in the previous sections, there was a strong focus on developing semi-empirical parameterisations for the ion-ion recombination coefficient within the atmospheric community. On the other hand, in the physical chemistry community, the search for more refined theories progressed further. This research soon encompassed ion-aerosol attachment processes and it became apparent that the microscopic mechanisms in the close vicinity of the ions and aerosol particles before and during collision could not be ignored when developing the recombination theory. The limiting sphere approach appeared to be advantageous to study these processes theoretically. In short, the limiting sphere is the area around an ion in which the collision with the second ion of opposite charge occurs. The limiting sphere and its radius are defined slightly differently depending on the theory. A sphere of radius $d$, in which the recombination happens, has already been described by Thomson (1924), as mentioned earlier (see Eq. (3) and (4)). In Fig. 1, we depict a schematic for the limiting sphere and the relevant associated processes. In Fig. 1 (a), an ion (white circle) approaches the ion in the centre (black circle) which has the opposite charge. The approaching ion experiences its last collision with a neutral gas molecule approximately one mean free path away from the limiting sphere. When entering the limiting sphere, the white ion collides with another neutral gas molecule, a process also called three-body trapping, because the gas molecule, which is the third body, "traps" the white ion inside the limiting sphere of the centre ion. However, not all of these collisions lead to the recombination of the two ions. This probability is accounted for in many theories. Two possible outcomes of the third-body collision are shown as cases 1 and 2 in Fig. 1 (b). Note that this depiction of the limiting sphere is just for illustration purposes; the different definitions will be discussed below. While a comprehensive review of all the theoretical work, model simulations and experiments that have been carried out on this topic is beyond the scope of this work, we would like to highlight the most important milestones and recent discussions in order to identify the potential of these approaches for their application to the lower atmosphere. 

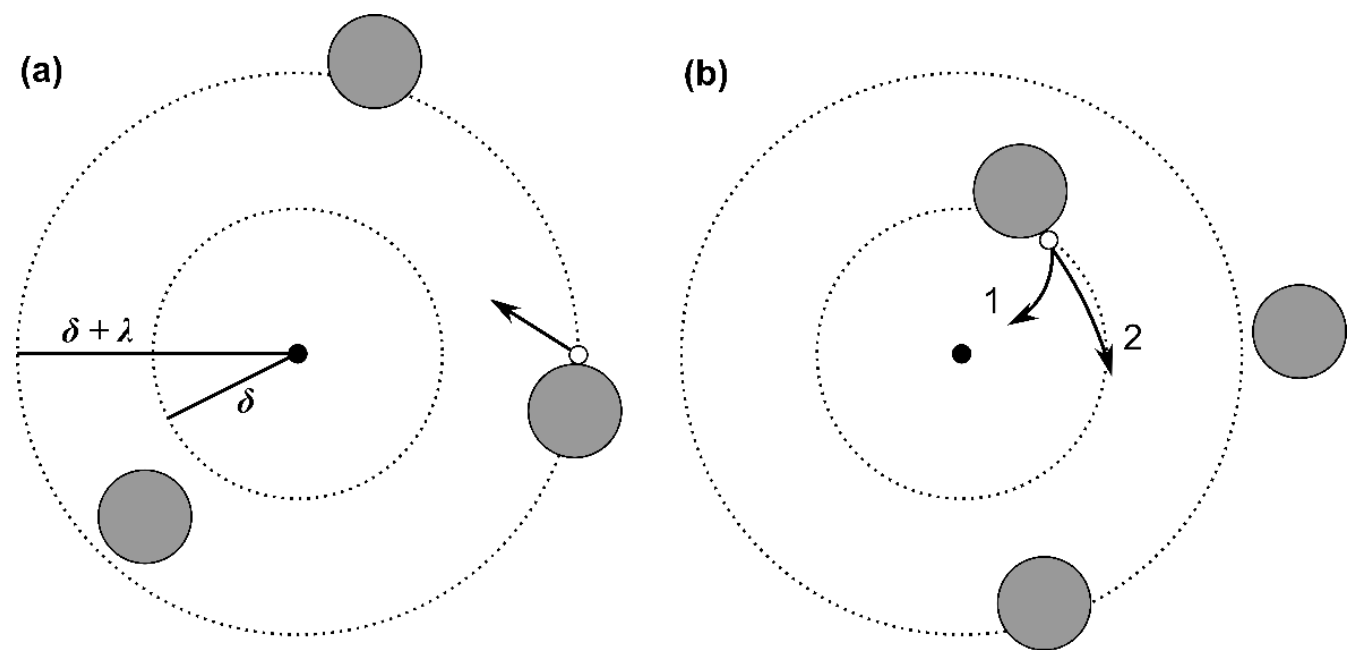

315 Figure 1: Schematic of the limiting sphere, based on López-Yglesias and Flagan (2013) and Tamadate et al. (2020). The black point in the centre represents an ion and the white point represents an ion of opposite sign, while the grey circles represent neutral gas molecules. The inner dotted circle $\delta$ is the limiting sphere, while the outer dotted circle $\delta+\lambda$ describes the radius of the inner sphere plus one mean free path of the white ion. The spheres are defined differently in various theories; this schematic depicts one option of many. a) The approaching white ion experiences its last collision with a neutral gas molecule outside the limiting sphere, on average one mean free path away from the surface of the limiting sphere. b) The white ion collides with another neutral gas molecule, this time leading to it entering the limiting sphere. In case 1, it collides and subsequently recombines with the black ion of opposite sign. In case 2 , no ion-ion collision and recombination occur and the white ion leaves the limiting sphere.

Natanson (1959a) (English translation of the original in Russian: Natanson (1959b)) developed a theory to unify Thomson's (low pressure) and Langevin's (high pressure) approaches. The original formula is given in the Gaussian CGS system of units, however, Tamadate et al. (2020) provided an SI version of Natanson's equation, as shown in Eq. (26).

$\alpha=\frac{\pi \cdot d^{2} \cdot v_{\mathrm{rel}} \cdot \varepsilon_{\mathrm{N}} \cdot\left[1+\frac{e^{2} \cdot \lambda}{4 \pi \cdot \varepsilon_{0} \cdot d \cdot(d+\lambda) \cdot k_{\mathrm{B}} T}\right] \cdot \exp \left(\frac{e^{2}}{4 \pi \cdot \varepsilon_{0} \cdot(d+\lambda) \cdot k_{\mathrm{B}} T}\right)}{1+\frac{\pi \cdot \varepsilon_{0} \cdot d^{2} \cdot \varepsilon_{\mathrm{N}} \cdot k_{\mathrm{B}} T}{e^{2} \cdot \lambda} \cdot\left[1+\frac{e^{2} \cdot \lambda}{4 \pi \cdot \varepsilon_{0} \cdot d \cdot(d+\lambda) \cdot k_{\mathrm{B}} T}\right] \cdot\left[\exp \left(\frac{e^{2}}{4 \pi \cdot \varepsilon_{0} \cdot(d+\lambda) \cdot k_{\mathrm{B}} T}\right)-1\right]}$, with

$v_{\text {rel }}=\sqrt{\frac{8 \cdot k_{\mathrm{B}} T}{\pi \cdot m}}$,

$\varepsilon_{\mathrm{N}}=2 w-w^{2}$,

$w=1+2 \cdot\left|\frac{\exp (-x)}{x^{2}}+\frac{\exp (-x)}{x}-\frac{1}{x^{2}}\right|$, and

$330 x=\frac{2 \cdot d}{\lambda}$,

where $d$ is the ion-ion trapping distance, $v_{\text {rel }}$ is the mean relative thermal speed of the ions, $\varepsilon_{\mathrm{N}}$ is the probability that one ion collides with a gas molecule while the other ion is at a distance $<d$ (also named "absorption coefficient"), $\varepsilon_{0}$ is the vacuum permittivity, $k_{\mathrm{B}}$ is the Boltzmann constant, and $m$ is the reduced mass. Note the use of the absolute value in Eq. (29), which is otherwise identical to Eq. (11). According to Gringel et al. (1978), $\varepsilon_{\mathrm{N}}=1$ at the Earth's surface and decreases with increasing altitude $(0.75$ at $10 \mathrm{~km}$ and 0.28 at $20 \mathrm{~km})$.

In order to use Natanson's theory, the trapping distance as well as the mean free path of the approaching ion must be known. Hoppel and Frick (1986) have calculated the recombination coefficient as a function of the trapping distance for different ionic 
masses. Assuming a recombination coefficient of $1.7 \cdot 10^{-6} \mathrm{~cm}^{3} \mathrm{~s}^{-1}$, the trapping distance is given as approximately $8 \mathrm{~nm}$ for an ion mass of $28.8 \mathrm{amu}, 14 \mathrm{~nm}$ for $60 \mathrm{amu}$, and $23 \mathrm{~nm}$ for $150 \mathrm{amu}$. At this point, it is worthwhile noting that the initial problem is to calculate $\alpha$ from a known $d$, whereas here, the value for $d$ needs to be first derived from a known $\alpha$. Gringel et al. (1978) conducted experiments in the atmosphere between 4 and $25 \mathrm{~km}$ over northern Germany in August and October 1976 to determine the ion-ion recombination coefficient and the ion-aerosol attachment coefficient. They found their experimentally derived $\alpha$ values ( 1 to $2.5 \cdot 10^{-6} \mathrm{~cm}^{3} \mathrm{~s}^{-1}$ for the troposphere) to be in good agreement with the theoretical one derived by Natanson (1959a) up to an altitude of $20 \mathrm{~km}$, i.e. within the three-body collision regime.

345 Natanson (1960a) (English translation of the original in Russian: Natanson (1960b)) expanded his approach to the attachment of ions to particles, while further theoretical development by other authors was later focussed on the ion-aerosol attachment, including the work of Fuchs (1963), who discussed the limiting sphere theory in the context of aerosol charge distribution. According to Fuchs, the limiting sphere is defined as a concentric sphere around the particle or ion with a radius of the distance at which the other ion collides with a neutral gas molecule for the last time before the ion-aerosol attachment or ion-ion recombination takes place. Outside the sphere, continuum equations are used, whereas inside the sphere, kinetic theory is applied because steady-state, rather than equilibrium conditions, are valid inside the limiting sphere (Fuchs, 1963; Hoppel and Frick, 1986). Coulomb as well as image forces are taken into account in this theory. The radius $\delta_{\mathrm{F}}$ of the limiting sphere is given in Eq. (31) (Fuchs, 1963), based on considerations by Wright (1960):

$\delta_{\mathrm{F}}=\frac{a^{3}}{\lambda^{2}} \cdot\left[\frac{1}{5} \cdot\left(1+\frac{\lambda}{a}\right)^{5}-\frac{1}{3} \cdot\left(1+\frac{\lambda^{2}}{a^{2}}\right) \cdot\left(1+\frac{\lambda}{a}\right)^{3}+\frac{2}{15} \cdot\left(1+\frac{\lambda^{2}}{a^{2}}\right)^{2.5}\right]$,

where $a$ is the particle radius (also denominated as the collision radius by Tamadate et al. (2020)) and $\lambda$ is the mean free path of the ion. Although Fuchs (1963) did not provide a formula for $\alpha$ himself, Tamadate et al. (2020) have used Fuchs's approach to derive the ion-ion recombination coefficient; this will be discussed later in this section.

However, there are two main problems with the theory of Fuchs (1963). Firstly, it ignores the three-body trapping, i.e. collisions of the two ions (or the ion and the particle) with neutral gas molecules (Hoppel and Frick, 1986; Tamadate et al., 2020). Threebody trapping becomes increasingly more relevant for aerosol particles approaching ionic sizes (or when two ions recombine) and when the pressure is relatively high, as is the case in the lower atmosphere. Secondly, an ion entering the limiting sphere of another ion with the opposite sign does not follow the thermal equilibrium distribution; stronger forces towards the centre are experienced by the incoming ion because of their mutual attraction (Gopalakrishnan and Hogan, 2012; Tamadate et al., 2020).

365 Subsequently, Hoppel and Frick (1986) developed a theory for ion-aerosol attachment based on Natanson (1960a), Keefe et al. (1968), and Hoppel (1977) that uses the limiting sphere approach and includes image forces and three-body trapping. The principle of their theory is that the inner ion current is proportional to the ion concentration at the limiting sphere radius $\delta$, (which will be defined later), while the ion current outside the limiting sphere is defined based on the macroscopic ion concentration so that, at $\delta^{\prime}$, Eq. (32) is yielded for the ion-aerosol attachment coefficient: 


$$
\beta^{k}=\frac{F \cdot \exp \left(\frac{-\Phi^{k}(\delta \prime)}{k_{\mathrm{B}} T}\right)}{1+\frac{F \cdot \exp \left(\frac{-\Phi^{k}(\delta \prime)}{k_{\mathrm{B}} T}\right)}{4 \cdot \pi \cdot D} \cdot \int_{\delta^{\prime}}^{\infty} \frac{\exp \left(\frac{\left(-\Phi^{k}(r)\right.}{k_{\mathrm{B}} T}\right)}{r^{2}} \mathrm{~d} r},
$$

where $\beta^{k}$ is the ion-aerosol attachment coefficient, $k$ is the number of elementary charges of the aerosol particle, $F$ is a proportionality constant, $\Phi^{k}(r)$ is the potential, $D$ is the diffusion coefficient, and $r$ is the radius which is to be integrated. Hoppel and Frick (1986) introduced the concept of the image capture distance $\Delta$; this is defined as the distance at which an ion is captured by the image force it experiences (based on Keefe et al. (1968) and Hoppel (1977)). The image force becomes more dominant compared to the Coulomb force when the particle radius increases, however, only including the image forces does not completely solve the problem. Keefe et al. (1968) assumed that the ion is in free flight, infinitely far away from the particle, but in reality, the ion collides with third bodies along the way and the last collision is about one mean free path away from the image capture sphere (Hoppel and Frick, 1986). Hence, the ion-aerosol trapping distance, or three-body trapping distance $\delta$ (without the prime), is introduced. However, it is impossible to determine this distance theoretically (Brueckner, 1964; Hoppel and Frick, 1986), but it is empirically well known for the case of ion-ion trapping (Hoppel and Frick, 1986). Hoppel and Frick (1986) show that the limiting sphere radius is defined differently depending on the relation of the image capture distance $\Delta$ and the three-body trapping distance $\delta_{3}$, as indicated in Eq. (33a) and (33b):

$\delta^{\prime}=\Delta+\lambda$, for $\Delta>\delta_{3}$ and

$\delta^{\prime}=\delta_{3}+\lambda$, for $\Delta<\delta_{3}$.

385 Eq. (33a) applies for a particle radius greater than $40 \mathrm{~nm}$. For smaller particle radii and especially for the ion-ion recombination, Eq. (33b) is valid. Hence, for the case of the ion-ion recombination, which is the main focus of this work, the limiting sphere is merely defined by the three-body trapping process, while the image forces can be neglected. The reported value for the attachment coefficient of a singly charged particle smaller than $2 \mathrm{~nm}$ in radius and an ion of opposite sign approaches $1.3 \cdot 10^{-}$ ${ }^{6} \mathrm{~cm}^{3} \mathrm{~s}^{-1}$ and, thus, approaches the ion-ion recombination coefficient itself. Hoppel and Frick (1986) showed that Fuchs's theory would lead to an ever-growing underestimation of the attachment coefficient for decreasing particle radii (e.g. $4.4 \cdot 10^{-}$ ${ }^{7} \mathrm{~cm}^{3} \mathrm{~s}^{-1}$ for a $1 \mathrm{~nm}$ radius) due to the negligence of the three-body trapping. However, Tamadate et al. (2020) criticised Hoppel and Frick (1986) on two points. Firstly, Hoppel and Frick do not provide a calculation of $\Delta$. In the case of ion-ion recombination, this is of no great concern. Secondly, they do not discuss the effect of changing pressure on the trapping distance. Hence, the approach of Hoppel and Frick (1986) is not suitable to determine $\alpha$ theoretically according to Tamadate et al. (2020). Nevertheless, López-Yglesias and Flagan (2013) have improved some approximations made by Hoppel and Frick (1986) and developed a model to calculate the ion-aerosol attachment for aerosol particles of different sizes and charges. The amendment of using a Maxwellian speed distribution for the ion instead of a fixed average speed led to the most significant of the deviations from Hoppel and Frick's model.

Tamadate et al. (2020) recently reported a molecular dynamics (MD) approach to determine the ion-ion recombination coefficient. Due to the necessary computing resources, applying an MD simulation for the whole range in which the two ions experience mutual Coulomb interaction is not feasible. Thus, they restricted the MD simulation to the limiting sphere while 
using the continuum (diffusion) equations outside the limiting sphere. They conducted recombination simulations for $\mathrm{NH}_{4}^{+}$ and $\mathrm{NO}_{2}{ }^{-}$in $\mathrm{He}$ at $300 \mathrm{~K}$ and $10^{2}$ to $10^{5} \mathrm{hPa}$. In order to derive the recombination coefficient, they used two different approaches: the theory by Fuchs (1963) and the one by Filippov (1993). The formula based on Fuchs's theory, Eq. (34), contains $\beta_{\delta}$, the ion-ion collision rate coefficient at distance $\delta$, which can be compared conceptually to the probabilities $\varepsilon$ of successful collisions between two ions or an ion and a particle in Thomsonian theories. Tamadate et al. (2020) derived $\beta_{\delta}$ with the help of Filippov (1993) (Eq. (35) and (36)):

$\alpha=\frac{\left(D_{+}+D_{-}\right) \cdot e^{2}}{\varepsilon_{0} \cdot k_{\mathrm{B}} T \cdot\left[1-\exp \left(\frac{-e^{2}}{4 \pi \cdot \varepsilon_{0} \cdot k_{\mathrm{B}} T \cdot \delta_{\mathrm{F}}}\right)\right]} \cdot\left(1+\frac{\left(D_{+}+D_{-}\right) \cdot e^{2}}{\beta_{\delta} \cdot \varepsilon_{0} \cdot k_{\mathrm{B}} T \cdot\left[\exp \left(\frac{e^{2}}{4 \pi \cdot \varepsilon_{0} \cdot k_{\mathrm{B}} T \cdot \delta_{\mathrm{F}}}\right)-1\right]}\right)^{-1}$, with

$\beta_{\delta}=\pi \cdot a^{2} \cdot\left(\frac{8 k_{\mathrm{B}} T}{\pi \cdot m}\right)^{0.5} \cdot \gamma(a)$, and

$410 \gamma(a)=1+\frac{e^{2}}{4 \pi \cdot \varepsilon_{0} \cdot k_{\mathrm{B}} T} \cdot\left(\frac{1}{a}-\frac{1}{\delta_{\mathrm{F}}}\right)$,

where $D_{+}$and $D_{-}$are the diffusion coefficients of the positive and negative ions, respectively, $e$ is the electron charge, $\varepsilon_{0}$ is the permittivity of vacuum, $\delta_{\mathrm{F}}$ is the radius of the limiting sphere (according to Fuchs), $\beta_{\delta}$ is the ion-ion collision rate coefficient at distance $\delta$ (i.e. on the surface of the limiting sphere), and $m$ is the reduced mass of the ions.

For the MD simulations, Tamadate et al. (2020) implemented the theory of Filippov (1993), who examined the ionic charging

415 of small aerosol particles with respect to the Knudsen number, which was, again, based on the considerations of Fuchs (1963). Tamadate et al. (2020) presented an equation (Eq. (37)) that defines the ion-ion recombination coefficient and which already includes the collision probability for ions entering the limiting sphere, $p_{\delta}$, and is independent of $\beta_{\delta}$ :

$\alpha=\frac{4 \pi \cdot\left(D_{+}+D_{-}\right) \cdot \delta \cdot \psi_{\delta}}{1-\exp \left(-\Psi_{\delta}\right)} \cdot\left[1+\left(\frac{\pi}{2}\right)^{0.5} \cdot \frac{2-p_{\delta}}{p_{\delta}} \cdot K n_{\delta} \cdot \frac{\Psi_{\delta}}{\exp \left(\Psi_{\delta}\right)-1}\right]^{-1}$, with

$\Psi_{\delta}=\frac{e^{2}}{4 \pi \cdot \varepsilon_{0} \cdot k_{\mathrm{B}} T \cdot \delta_{\mathrm{F}}}$, and

$420 K n_{\delta}=\left(\frac{m}{k_{\mathrm{B}} T}\right)^{0.5} \cdot \frac{D_{+}+D_{-}}{\delta_{\mathrm{F}}}$,

where $p_{\delta}$ is the collision probability for ions entering the limiting sphere, $\Psi_{\delta}$ is the ratio of Coulomb and thermal energy at the limiting sphere surface, and $K n_{\delta}$ is the Knudsen number for the limiting sphere. In order to compute $p_{\delta}$, a minimum of 100 collision events were simulated. Three scenarios occurred in the simulations: collision of the two ions, non-collision, and an orbiting of one ion around the other. While the calculations require an input for the limiting sphere radius $\delta$ and the collision radius of the ions, the results need to be independent of these parameters (Tamadate et al., 2020). They found that in order to yield a constant $\alpha$ value, $\delta$ must be larger than 0.5 times Fuchs's limiting sphere radius given by Eq. (31). For smaller radii, the assumption of continuum transport inside the limiting sphere is no longer valid, as $\alpha$ was found not to stay constant with decreasing radii. The MD simulations were run for different conditions: with and without the influence of electrostatic forces, as well as with and without surrounding neutral gas atoms. Including or excluding the electrostatic forces yielded almost no 430 difference. When excluding the orbiting results, the simulations without the surrounding gas (i.e. no third-body collision) agreed excellently with Fuchs (1963), whereas the agreement with Hoppel and Frick (1986) was overall much poorer because 
their theory does not converge to the two-body scenario for decreasing pressures. When including the neutral gas atoms in the simulation, Tamadate et al. (2020) observed that collisions are neither certain nor prohibited for specific speeds or angles, underlining the need to include neutral gas molecules in MD simulations. Moreover, they derived a recombination rate of $4351.1 \cdot 10^{-6} \mathrm{~cm}^{3} \mathrm{~s}^{-1}$ for $\mathrm{NH}_{4}{ }^{+}$and $\mathrm{NO}_{2}^{-}$in $\mathrm{He}$ at $300 \mathrm{~K}$ and $1000 \mathrm{hPa}$; this is in excellent agreement with Lee and Johnsen (1989) who reported $1.1 \cdot 10^{-6} \mathrm{~cm}^{3} \mathrm{~s}^{-1}$ for $\mathrm{H}_{3} \mathrm{O}^{+}\left(\mathrm{H}_{2} \mathrm{O}\right)_{2,3}$ and $\mathrm{NO}_{3}{ }^{-}$in $\mathrm{He}$ at 295 to $300 \mathrm{~K}$ and $1013 \mathrm{hPa}$. In addition, the result at a lower pressure of approximately $300 \mathrm{hPa}, 6.7 \cdot 10^{-7} \mathrm{~cm}^{3} \mathrm{~s}^{-1}$, agreed well with Lee and Johnsen (1989) $\left(7.0 \cdot 10^{-7} \mathrm{~cm}^{3} \mathrm{~s}^{-1}\right)$. Apart from the increase of $\alpha$ with increasing pressure below atmospheric pressures, they could observe $\alpha$ decreasing with increasing pressure above atmospheric pressures, as predicted by Langevin theory. While the approach of Tamadate et al.

440 (2020) is very promising, they correctly emphasise the need for hybrid continuum-MD simulations with $\mathrm{N}_{2}$ and $\mathrm{O}_{2}$, instead of $\mathrm{He}$, in order to achieve results comparable to atmospheric conditions. Simulation experiments at temperatures and pressures representative of the different layers of the lower atmosphere could provide a better insight into the variation of the ion-ion recombination coefficient $\alpha$ in the atmosphere. Eventually, parameterisations are needed for everyday use because MD simulations require advanced computing power and experience.

\section{Comparison of the parameterisations}

In Table 2, all parameterisations, field and laboratory data sets and model results discussed in the previous sections are listed for a better overview. In the following, the abbreviations listed in Table 2 will be used to address the different parameterisations, data sets, and model results. 
450 Table 2: List of all theories, parameterisations, data sets, and models used for comparison.

\begin{tabular}{|c|c|c|c|}
\hline Study & Abbr. & Formula (for parameterisations) / Range (for data sets) & \\
\hline \multicolumn{4}{|c|}{ Theories and parameterisations } \\
\hline Gardner, 1938 & $\mathrm{Ga} 38$ & $\alpha=1.9 \cdot 10^{-5} \cdot\left(\frac{273}{T}\right)^{1.5} \cdot\left(\frac{1}{M}\right)^{0.5} \cdot \varepsilon_{\mathrm{T}}(T, p)$ & $\varepsilon_{\mathrm{T}}:$ Eq. (10) to (12) \\
\hline Loeb, 1955/1960 & Lo60 & $\alpha=1.73 \cdot 10^{-5} \cdot\left(\frac{273}{T}\right)^{1.5} \cdot\left(\frac{1}{M}\right)^{0.5} \cdot \varepsilon_{\mathrm{T}}(T, p)$ & $\varepsilon_{\mathrm{T}}:$ Eq. (10) to (12) \\
\hline Israël, 1957/1971 & Is57 & $\alpha=1.95 \cdot 10^{-6} \cdot\left(\frac{273}{T}\right)^{1.5} \cdot f(T, p)$ & $f:$ Eq. (16) and (12) \\
\hline Natanson, 1959 & $\mathrm{Na59}$ & 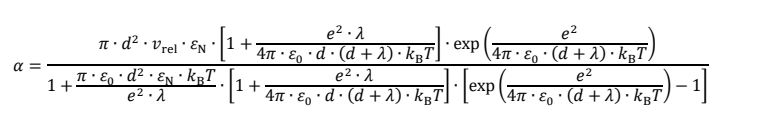 & $\begin{array}{l}v_{\text {rel }}, \varepsilon_{\mathrm{N}}: \text { Eq. }(27) \text { to } \\
(30)\end{array}$ \\
\hline Hickman, 1979 & Hi79 & $\alpha=2.28 \cdot 10^{-5} \cdot\left(\frac{T}{300}\right)^{-0.5} \cdot m^{-0.5} \cdot E A^{-0.4}$ & \\
\hline Miller, 1980 & Mi80 & $\alpha=5.33 \cdot 10^{-7} \cdot\left(\frac{T}{300}\right)^{-0.5} \cdot m^{-0.5} \cdot E A^{-0.4}$ & for $T \leq 1000 \mathrm{~K}$ \\
\hline Smith and Adams, 1982 & SA82 & $\alpha=1.63 \cdot 10^{-5} \cdot e^{-\frac{h}{7.38}}+5.25 \cdot 10^{-8}$ & $\begin{array}{l}\text { valid from } 10 \text { to } \\
60 \mathrm{~km}\end{array}$ \\
\hline Arijs et al., 1983 & Ar83 & $\alpha=6 \cdot 10^{-8} \cdot\left(\frac{300}{T}\right)^{0.5}+1.25 \cdot 10^{-25} \cdot[\mathrm{M}] \cdot\left(\frac{300}{T}\right)^{4}$ & {$[\mathrm{M}]:$ Eq. (21b) } \\
\hline Brasseur and Chatel, 1983 & $\mathrm{BC} 83$ & $\alpha=6 \cdot 10^{-8} \cdot\left(\frac{300}{T}\right)^{0.5}+6 \cdot 10^{-26} \cdot[\mathrm{M}] \cdot\left(\frac{300}{T}\right)^{4}$ & {$[\mathrm{M}]:$ Eq. (21b) } \\
\hline Bates, 1985 & $\mathrm{Ba} 85$ & $\alpha=5.33 \cdot 10^{-6} \cdot e^{-0.111 \cdot h}$ & $\begin{array}{l}\text { valid from } 10 \text { to } \\
25 \mathrm{~km}\end{array}$ \\
\hline Hoppel and Frick, 1986 & HF86 & see Ta20 & $\beta_{\delta}, \gamma$ : Eq. (43) to (47) \\
\hline Tamadate et al., 2020 & Ta20 & 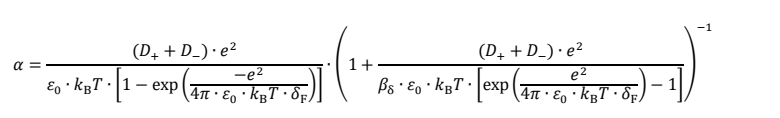 & $\begin{array}{l}\beta_{\delta}, \gamma: \text { Eq. (35) and } \\
(36)\end{array}$ \\
\hline \multicolumn{4}{|l|}{ Field data } \\
\hline Gringel et al., 1978 & Gr78 & \multicolumn{2}{|c|}{$\alpha$ derived from measurements of $q$ and air conductivity at 4 to $30 \mathrm{~km}$} \\
\hline Rosen and Hofmann, 1981 & RH81 & \multicolumn{2}{|l|}{$\alpha$ derived from measurements of $q$ and $n_{+}$at 2 to $35 \mathrm{~km}$} \\
\hline Morita, 1983 & Mo83 & \multicolumn{2}{|l|}{$\alpha$ derived from measurements of $q$ and $n_{+}$at 3 to $35 \mathrm{~km}$} \\
\hline
\end{tabular}

\section{Laboratory data}

Franchin et al., 2015
Fr15 $\alpha(T)$ for $R H=$ const. and $\alpha(R H)$ for $T=$ const.; $\alpha \sim T^{-3}$

\section{Model data}

Bates, 1982

Ba82 Monte Carlo simulation of $\alpha_{3}, \Delta \alpha_{2}$ and $\alpha_{\mathrm{T}}$ for 0 to $40 \mathrm{~km}$ in $5 \mathrm{~km}$ steps 


\subsection{Sensitivity study of the limiting sphere theories}

The limiting sphere theories are influenced by certain input parameters, such as the masses of the two ions, the ion mobilities or diffusivities, and the limiting sphere radius, apart from the temperature and pressure. Small changes in these parameters can already have a significant impact on the resulting ion-ion recombination coefficient.

455 For Na59, we utilised Eq. (26) to (30) and calculated $\lambda$ according to Eq. (40) to (42) (Tamadate et al., 2020):

$\lambda=\left(D_{+}+D_{-}\right) \cdot\left(\frac{\pi \cdot m}{8 \cdot k_{\mathrm{B}} T}\right)^{0.5}$,

where $m$ is the reduced mass of the two ions and $D_{+}$and $D_{-}$are calculated according to Eq. (41a) and (41b), respectively:

$D_{+}=D_{+, 0} \cdot \frac{p_{0}}{p} \cdot\left(\frac{T}{T_{0}}\right)^{1.75}$ and

$D_{-}=D_{-, 0} \cdot \frac{p_{0}}{p} \cdot\left(\frac{T}{T_{0}}\right)^{1.75}$, with

$460 D_{0}=\frac{\mu_{0} \cdot k_{\mathrm{B}} T}{e}$,

where $D_{+, 0}$ and $D_{-, 0}$ are the reference diffusivities calculated from the reference ion mobility at standard pressure and temperature, $\mu_{0}$, according to Eq. (42), given by López-Yglesias and Flagan (2013). The temperature dependence of 1.75 for $D$ is taken from Tang et al. (2014). (López-Yglesias and Flagan (2013) use $T^{2}$ and the Chapman-Enskog theory predicts $T^{1.5}$ (Chapman and Cowling, 1960).)

465 We calculated Ta20 based on the derivations after Fuchs (1963) (Eq. (34) to (36)) and after Filippov (1993) (Eq. (37) to (39)), using Eq. (40) to (42) likewise. However, both derivations yielded the same results within our limits of uncertainty, therefore, for a better overview, for Ta20 we only show the results based on Fuchs.

In order to model the recombination coefficient according to HF86, we used the set of formulae provided by Tamadate et al. (2020), shown in Eq. (34) and (43) to (47). For Hoppel and Frick's $\alpha$, they also used Eq. (34), which they derived from Fuchs's theory. However, $\beta_{\delta}$, the ion-ion collision rate coefficient at distance $\delta$, is defined differently for Hoppel and Frick, given in Eq. (43). Here, the ion-ion collision rate $\beta_{\delta}$ is not directly dependent on the particle radius $a$ (see Eq. (35)), but on the ion-ion trapping distance $d$. Furthermore, the additional probability factor for ions entering the trapping sphere, $p_{\mathrm{d}}$, is introduced to the ion-ion collision rate:

$\beta_{\delta}=\pi \cdot d^{2} \cdot\left(\frac{8 k_{\mathrm{B}} T}{\pi \cdot m}\right)^{0.5} \cdot \gamma(d) \cdot p_{\mathrm{d}}$, with

$475 \gamma(d)=1+\frac{e^{2}}{4 \pi \cdot \varepsilon_{0} \cdot k_{\mathrm{B}} T} \cdot\left(\frac{1}{d}-\frac{1}{\delta_{\mathrm{F}}}\right)$,

$p_{\mathrm{d}}=1-\frac{\lambda^{2}}{2 \cdot d^{2}} \cdot\left(1-\exp \left(\frac{-2 \cdot d \cdot \cos \theta}{\lambda}\right) \cdot\left(1+\frac{2 \cdot d}{\lambda} \cdot \cos \theta\right)\right)$,

$\theta=\sin ^{-1}\left(\frac{b}{d}\right)$, and

$b=a \cdot \sqrt{1+\frac{e^{2}}{32 \cdot k_{\mathrm{B}} T \cdot \varepsilon_{0}} \cdot\left(\frac{1}{a}-\frac{1}{d}\right)}$,

where $\theta$ is the critical angle to enter the trapping sphere and $b$ is the critical collision parameter (Tamadate et al., 2020). 
480 For the particle radius $a$, we used the value of $0.335 \mathrm{~nm}$ provided by Tamadate et al. (2020). For the ion masses, we assumed $150 \mathrm{amu}$ in our sensitivity studies for both the negative and positive ions since the most abundant atmospheric ions are usually clustered with several water molecules (Viggiano and Arnold, 1995; Eisele and Hanson, 2000).

Using $\mu_{0}=1.2 \cdot 10^{-4} \mathrm{~m}^{2} \mathrm{~V}^{-1} \mathrm{~s}^{-1}$ (López-Yglesias and Flagan, 2013), the resulting value for $D_{+, 0}$ and $D_{-, 0}$ is $3.12 \cdot 10^{-6} \mathrm{~m}^{2} \mathrm{~s}^{-1}$. As the exact limiting sphere radius $d$ is uncertain, we studied three cases for Na59 and HF86: 18, 23 and $28 \mathrm{~nm}$ (23 nm is the proposed value of Hoppel and Frick (1986) for an ion of $150 \mathrm{amu}$, assuming an ion-ion recombination coefficient of $1.7 \cdot 10^{-}$ ${ }^{6} \mathrm{~cm}^{3} \mathrm{~s}^{-1}$ ). Ta20 is independent of $d$. We compared Na59 and HF86 for the three limiting sphere radii and show the results of this sensitivity study for an altitude range of 0 to $50 \mathrm{~km}$ in Fig 2 . Between 0 and $30 \mathrm{~km}$, the resulting recombination coefficients show the same trend for both theories and all three radii. Above $30 \mathrm{~km}$, HF86 decreases less strongly, converging towards a few times $10^{-8} \mathrm{~cm}^{3} \mathrm{~s}^{-1}$, whereas Na59 shows an almost constant decrease. Between 0 and $10 \mathrm{~km}$, the recombination coefficient 490 is almost constant for Na59 and HF86, however, a slight increase can be observed above $0 \mathrm{~km}$ before the decrease becomes effective. The maxima in $\alpha$ values are between 2 and $7 \mathrm{~km}$, depending on the theory and limiting sphere radius. HF86 shows a strong gradient in $\alpha$ between $0 \mathrm{~km}\left(\alpha=1.6 \cdot 10^{-6} \mathrm{~cm}^{3} \mathrm{~s}^{-1}\right)$ and its maximum at $5 \mathrm{~km}\left(2.8 \cdot 10^{-6} \mathrm{~cm}^{3} \mathrm{~s}^{-1}\right)$ for $d=28 \mathrm{~nm}$. The recombination coefficients for the least assumed limiting sphere radius, $18 \mathrm{~nm}$, and the greatest, $28 \mathrm{~nm}$, differ by roughly a factor of 2 for both theories at an altitude of $15 \mathrm{~km}$. From these results, it becomes obvious that the input values for the limiting sphere theories have to be chosen accurately in order to avoid greater uncertainties. This is not only the case for the limiting sphere radii, but also for the ion masses and the ion mobilities.

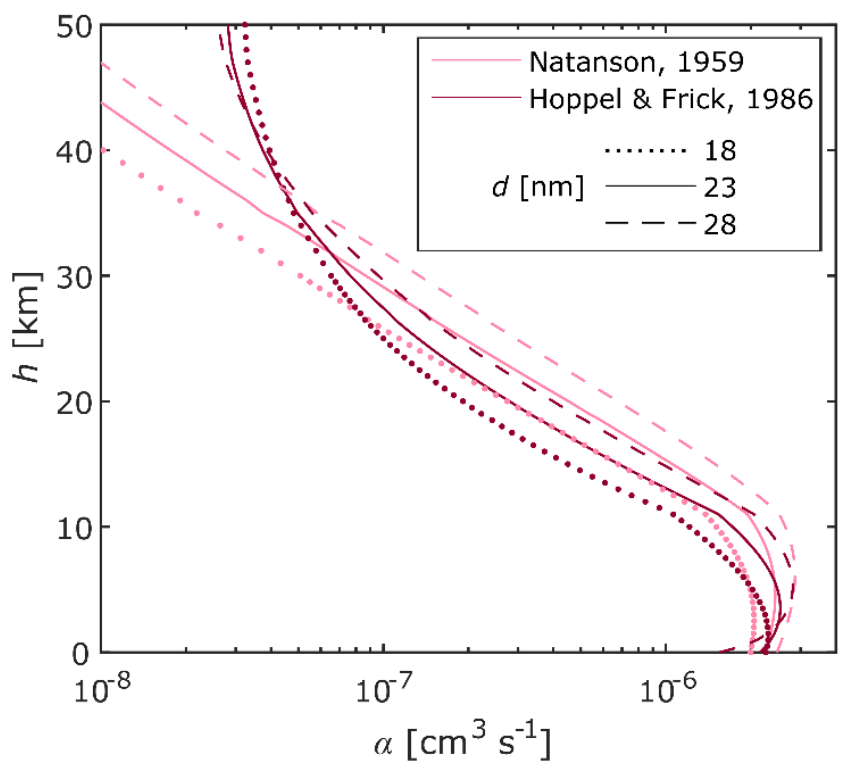

Figure 2: Sensitivity study of the ion-ion recombination coefficient $\alpha$ to different limiting sphere radii $d$ of the limiting sphere theories Na59 and HF86 for an altitude range of 0 to $50 \mathrm{~km}$. 


\subsection{Comparison to laboratory data}

In order to find the most accurate formula to parameterise the ion-ion recombination coefficient, we compare the above mentioned parameterisations and theories to the field, laboratory and model data.

In a first step, the parameterisations and theories are compared to the constant-pressure and temperature-dependent data set reported by Franchin et al. (2015). Here, only parameterisations are used that include the temperature as a parameter (i.e. Ga38, Is57, Na59, Lo60, Hi79, Mi80, Ar83, BC83, HF86, and Ta20). Parameterisations that predict $\alpha$ based solely on the altitude are, therefore, excluded (i.e. SA82 and Ba85). We used $m_{+}=m_{-}=150 \mathrm{amu}, \mu_{0}=1.2 \cdot 10^{-4} \mathrm{~m}^{2} \mathrm{~V}^{-1} \mathrm{~s}^{-1}$, and $E A=1 \mathrm{eV}$ (the electron affinity was derived from Hickman (1979) for $\mathrm{NO}_{3}{ }^{-}$reacting with $\left.\mathrm{H}_{3} \mathrm{O}^{+}\left(\mathrm{H}_{2} \mathrm{O}\right)_{3}\right)$. The result of the comparison is shown in Fig. 3. The temperature-dependent data points of Fr15 are shown in all three panels. For Fr15, there is a general trend towards higher recombination coefficient values for lower temperatures, although the fluctuation is comparably strong. In Fig.

5103 (a), the complex potential models Hi79 and Mi80 are plotted. At higher temperatures (278 and 293 K), Hi79 agrees well with Fr15, although it deviates at lower temperatures because there is almost no response to the changing temperature $\left(3.1 \cdot 10^{-}\right.$ ${ }^{6} \mathrm{~cm}^{3} \mathrm{~s}^{-1}$ at $218 \mathrm{~K}$ compared to $2.7 \cdot 10^{-6} \mathrm{~cm}^{3} \mathrm{~s}^{-1}$ at $293 \mathrm{~K}$ ). In addition, Hi79 does not reproduce the $\alpha$ value at standard conditions, $1.7 \cdot 10^{-6} \mathrm{~cm}^{3} \mathrm{~s}^{-1}$. The performance of Mi80 is poor, yielding values that are one to two orders of magnitude too low. The other semi-empirical parameterisations, Ga38, Is57, Lo60, Ar83, and BC83, agree within a reasonable range at ground-level temperatures (270 to $300 \mathrm{~K}$ ) (Fig. 3 (b)), especially the Thomsonian theories Ga38, Is57, and Lo60 which yield almost the same values. However, the Thomsonian and the semi-empirical theories (Ar83 and BC83) differ tremendously from each other for tropopause temperatures (around $220 \mathrm{~K}$ ). The weaker temperature dependence of the group Ga38, Is57, and Lo60 $\left(T^{-1.5}\right)$ results in a negligible increase of $\alpha$ with decreasing temperatures. The laboratory data of Fr15, on the other hand, show a stronger $T$ dependence (around $T^{-3}$ ) that is best reproduced by $\operatorname{Ar} 83$ and BC83, which assume a $T^{-5}$ dependence for the ternary recombination. This observation is to be expected, since a ternary recombination mechanism is supposed to be dominant at ground-level pressure. BC83 appears to reproduce the data points slightly better than Ar83. In Fig. 3 (c), the limiting sphere theories are shown. While Na59 and HF86 are in the same range as Fr15 for $278 \mathrm{~K}$ and $293 \mathrm{~K}$, they yield much lower values for cold temperatures compared to Fr15. HF86 shows an unexpected behaviour between 230 and $260 \mathrm{~K}$, with fluctuating $\alpha$ values that can even become negative. Ta20 yields values which are generally too low for the recombination coefficient, e.g. $3.4 \cdot 10^{-7} \mathrm{~cm}^{3} \mathrm{~s}^{-1}$ at $273 \mathrm{~K}$ and $1013 \mathrm{hPa}$. Thus, neither of the limiting sphere theories can reproduce the laboratory data satisfactorily. 
(a)
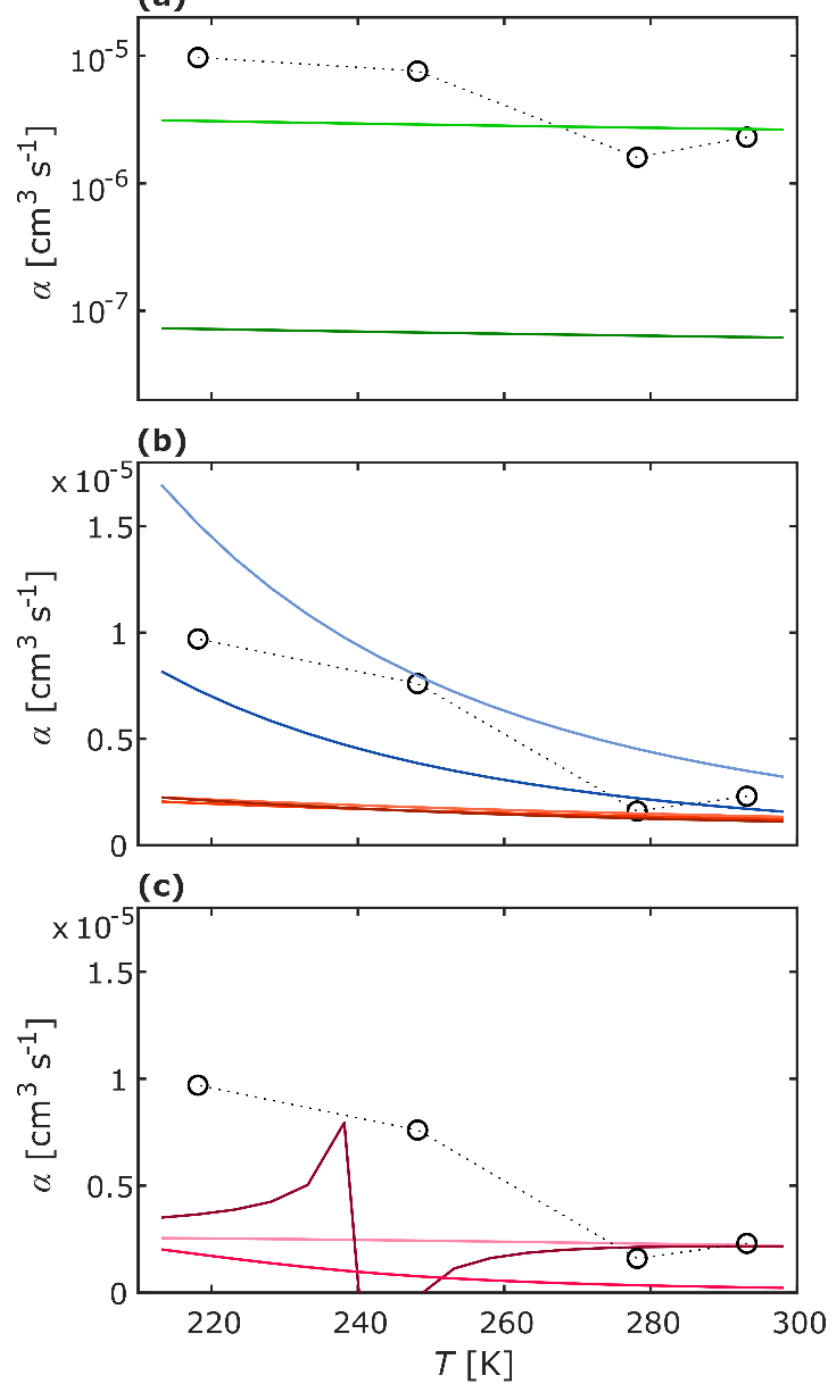

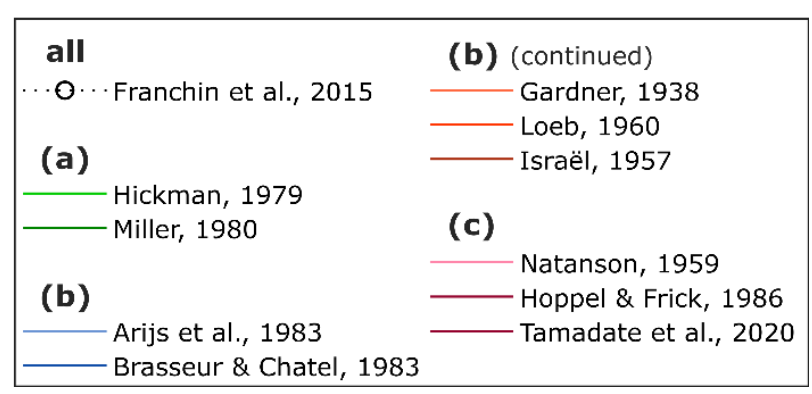

Figure 3: Parameterisations (solid lines) and laboratory data (circles) of the recombination coefficient $\alpha$ for the temperature range of 213 to $298 \mathrm{~K}$. a) Complex potential models Hi79 and Mi80 (note the logarithmic y-axis), b) Thomsonian theories (Ga38, Lo60, Is57) and semi-empirical parameterisations (Ar83, BC83), and c) limiting sphere theories (Na59, HF86, Ta20). In all panels, the data from Fr15 are shown. 
Franchin et al. (2015) have additionally used the model by López-Yglesias and Flagan (2013) to simulate the ion-ion recombination coefficient for the discussed temperature range. This model describes the ion-aerosol attachment coefficient, although it can also be applied to the special case of two ions recombining. However, the model was unable to reproduce the measured data in the low-temperature regime (Franchin et al., 2015).

\subsection{Comparisons to field and model data}

In a second step, the parameterisations and theories were compared to field and model data. The temperature, pressure and air density data of the US Standard Atmosphere were used here (National Oceanic and Atmospheric Administration et al., 1976). The results are plotted in Fig. 4. Here, the y-axis represents the altitude $h$ and the $\mathrm{x}$-axis represents the ion-ion recombination coefficient $\alpha$.

In Fig. 4 (a), the complex potential models of Hi79 and Mi80 are shown. In Fig. 4 (b), the Thomsonian theories of Ga38, Lo60, and Is57 are depicted. Figure 4 (c) shows the semi-empirical adjustments to the Thomson theory of Ar83 and BC83 as well as the Monte Carlo simulation of Ba82. Figure 4 (d) gives an overview of the solely altitude-dependent parameterisations of SA82 and Ba85, as well as all the field data sets of Gr78, RH81, and Mo83. In Fig. 4 (e), the results of the limiting sphere models (Na59, HF86, and Ta20) are plotted. For a better comparability, the measurements of RH81 are shown in all plots. It should be noted, however, that the data of RH81 and Mo83 are erroneous below $10 \mathrm{~km}$, although they are believed to be more accurate than the data of Gr78, as mentioned previously.

The parameterisation of Hi79 (Fig. 4 (a)) is within the correct order of magnitude for the lower part of the troposphere, however, this still yields too big a value for ground conditions $\left(2.7 \cdot 10^{-6} \mathrm{~cm}^{3} \mathrm{~s}^{-1}\right)$. The value slightly increases with increasing altitude up to $11 \mathrm{~km}\left(3.1 \cdot 10^{-6} \mathrm{~cm}^{3} \mathrm{~s}^{-1}\right)$ and stays practically constant above this altitude. Mi80, on the other hand, shows a poor performance again, being orders of magnitude too low with a recombination coefficient of 6.3 to $7.2 \cdot 10^{-8} \mathrm{~cm}^{3} \mathrm{~s}^{-1}$. Thus, both theories are not able to reproduce properly the field data.

The Thomsonian parameterisations (Fig. 4 (b)) are within the correct order of magnitude in the troposphere. The two early theories of Ga38 and Lo60 start with rather low values at ground level (1.4 and $1.3 \cdot 10^{-6} \mathrm{~cm}^{3} \mathrm{~s}^{-1}$, respectively) and describe a slight increase until $11 \mathrm{~km}$. Above this, the values decrease slightly and are in good accordance to RH81. Is57 describes a different curve, continuously increasing with altitude. Furthermore, the ground-level value of $1.2 \cdot 10^{-6} \mathrm{~cm}^{3} \mathrm{~s}^{-1}$ is comparably low which is remarkable since Israël used a value of $1.6 \cdot 10^{-6}$ for the Earth's surface to derive his simplified equation. Up to $8 \mathrm{~km}$, Is57 is in good accordance to Ga38 and Lo60, however, above $10 \mathrm{~km}$, where the measurements of RH81 can be considered as relatively accurate, it drifts away from the field data. 

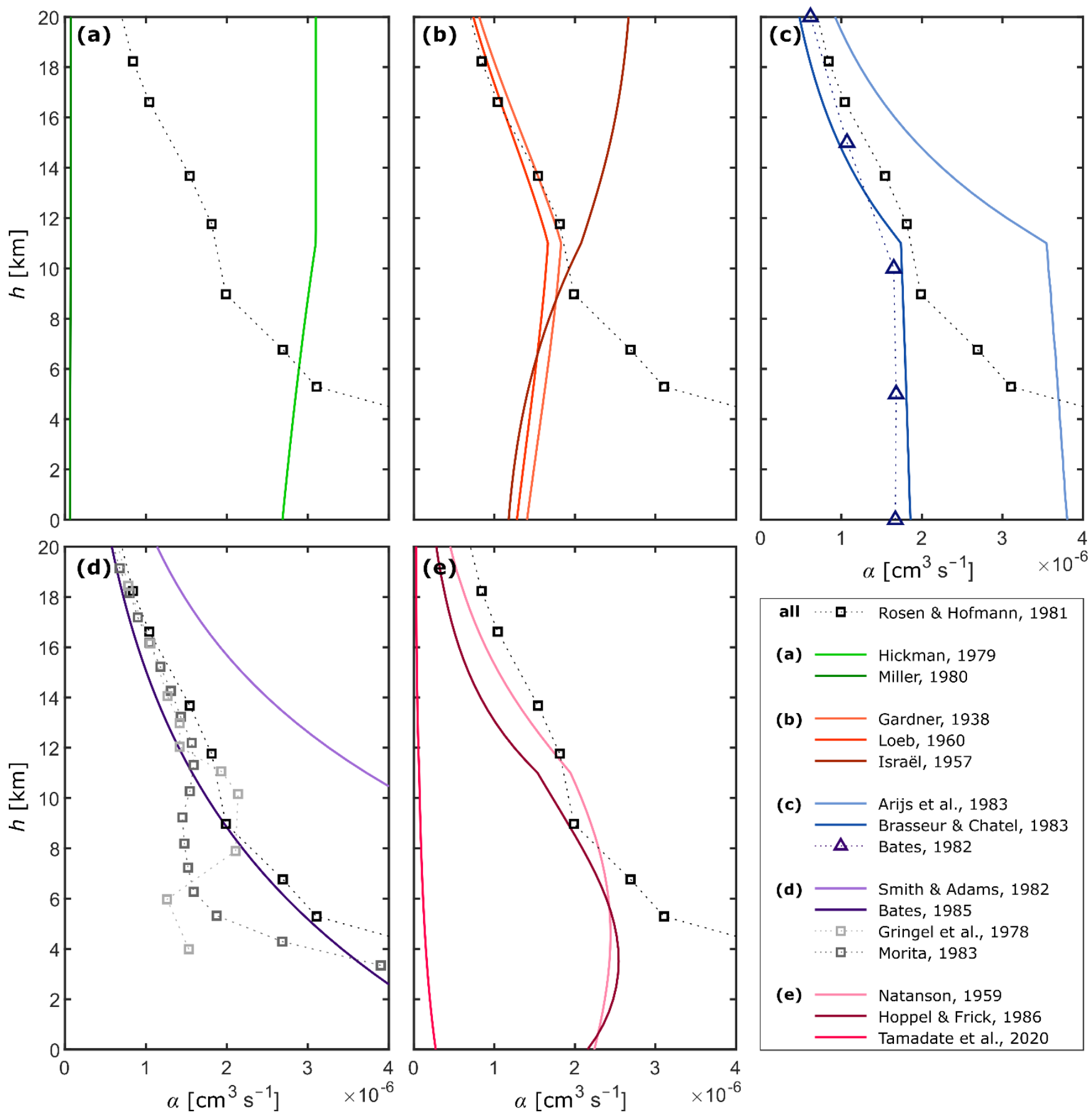

\begin{tabular}{|c|c|c|}
\hline all & $\cdots \mathbf{\square}$ & Rosen \& Hofmann, 1981 \\
\hline (a) & & $\begin{array}{l}\text { Hickman, } 1979 \\
\text { Miller, } 1980\end{array}$ \\
\hline (b) & & $\begin{array}{l}\text { Gardner, } 1938 \\
\text { Loeb, } 1960 \\
\text { Israël, } 1957\end{array}$ \\
\hline (c) & $\cdots \Delta$ & $\begin{array}{l}\text { Arijs et al., } 1983 \\
\text { Brasseur \& Chatel, } 1983 \\
\text { Bates, } 1982\end{array}$ \\
\hline (d) & $\begin{array}{l}\cdots \cdot \square \cdots \\
\cdots, \square \cdots\end{array}$ & $\begin{array}{l}\text { Smith \& Adams, } 1982 \\
\text { Bates, } 1985 \\
\text { Gringel et al., } 1978 \\
\text { Morita, } 1983\end{array}$ \\
\hline (e) & & $\begin{array}{l}\text { Natanson, } 1959 \\
\text { Hoppel \& Frick, } 1986 \\
\text { Tamadate et al., } 2020\end{array}$ \\
\hline
\end{tabular}

Figure 4: Parameterisations (solid lines), field data (squares), and model simulations (triangles) of the recombination coefficient $\alpha$ for the altitude range of 0 to $20 \mathrm{~km}$ for conditions of the US Standard Atmosphere. a) Complex potential models (Hi79, Mi80), b) Thomsonian theories (Ga38, Lo60, Is57), c) semi-empirical parameterisations (Ar83, BC83) and model simulation (Ba82), d) altitude-dependent parameterisations (SA82, Ba85) and field data (Gr78, RH81, Mo83), and e) limiting sphere theories (Na59, HF86, Ta20). The data points of RH81 are added to all panels for a better comparability. 
The model simulation of Ba82 (Fig. 4 (c)) yields a value of $1.7 \cdot 10^{-6} \mathrm{~cm}^{3} \mathrm{~s}^{-1}$ from ground level up to $10 \mathrm{~km}$. This value is in good agreement with independent laboratory measurements, yielding $(1.7 \pm 0.1) \cdot 10^{-6} \mathrm{~cm}^{3} \mathrm{~s}^{-1}$ at normal conditions (Lenz, 1932). Above $10 \mathrm{~km}$, the value decreases and approaches the measurements of RH81 with good agreement. The parameterisation of $\mathrm{BC} 83$ is able to closely represent $\mathrm{Ba} 82$, with slightly higher values up to $13 \mathrm{~km}$. The recombination coefficient only slightly decreases from 0 to $11 \mathrm{~km}$ for BC83 $\left(1.9 \cdot 10^{-6} \mathrm{~cm}^{3} \mathrm{~s}^{-1}\right.$ at ground level; $1.7 \cdot 10^{-6} \mathrm{~cm}^{3} \mathrm{~s}^{-1}$ at $\left.11 \mathrm{~km}\right)$, but decreases more dramatically above that altitude; this is because up to $11 \mathrm{~km}$, the decreasing temperature and the decreasing pressure nearly counterbalance. However, above $11 \mathrm{~km}$, the temperature stays constant while the pressure further decreases, leading to decreasing values of $\alpha$ altogether. The results of Ar83 also show this pattern but with much greater (and unrealistic) values overall; for instance, the ground-level coefficient of $3.8 \cdot 10^{-6} \mathrm{~cm}^{3} \mathrm{~s}^{-1}$ is beyond the range of uncertainty. The divergence between Ar83 and BC83 is due to the higher factor in the three-body term of the formula of Ar83 (see Eq. (20) and (22)). The curve eventually reaches closer to RH81 and BC83 at higher altitudes, when the two-body recombination process gains increasing importance.

The comparison of the three measurement campaigns (Gr78, RH81, Mo83) in Fig. 4 (d) reveals that above 12 km, the data points are in good agreement and can, therefore, be considered as reliable. Between 5 and $12 \mathrm{~km}$, the reported values differ by up to a factor of 2. Whilst RH81 and Mo83 describe relatively smooth curves, adjacent data points of Gr78 show a relatively strong amplitude for the recombination coefficient. As discussed previously, the values of RH81 and Mo83 cannot be used below approximately $9 \mathrm{~km}$. The solely altitude-dependent parameterisation of Ba85, which is valid between 10 and $25 \mathrm{~km}$, reproduces the measured data and the simulations by Ba82 quite well within its range of validity. The parameterisation of

585 SA82, however, yields values that are too high and is, therefore, not recommended.

In Fig. 5 (e), the limiting sphere theories Na59, HF86, and Ta20 are shown. Whilst Na59 and HF86 agree fairly well with each other, Ta20 yields $\alpha$ values which are one order of magnitude too low $\left(2.7 \cdot 10^{-6} \mathrm{~cm}^{3} \mathrm{~s}^{-1}\right.$ at ground level) and is, therefore, not recommended. Na59 and HF86 show maxima in the $\alpha$ values within the troposphere at 4.5 and $3.5 \mathrm{~km}$, respectively, while at ground level, they are slightly too high $\left(2.2 \cdot 10^{-6} \mathrm{~cm}^{3} \mathrm{~s}^{-1}\right)$ and, furthermore, they are lower than RH81 above $9 \mathrm{~km}$ (HF86) and $12 \mathrm{~km}(\mathrm{Na} 59)$.

To sum up the comparison, the field data of Gr78, RH81, and Mo83, the model calculation of Ba82, and the parameterisations of Ga38, Na59, Lo60, BC83 and Ba85 agree well between altitudes of 10 and $20 \mathrm{~km}$. At ground level, Ba82 and BC83 come closest to the independent laboratory measurements of $\alpha$. However, for the altitude range of slightly above 0 up to $10 \mathrm{~km}$, there is no benchmark available. It is reasonable to assume that the recombination coefficient essentially stays constant, a feature reproduced by the results of $\mathrm{Ba} 82$, Ar83, and BC83 in a first approximation. It cannot be excluded, however, that the value of $\alpha$ has a maximum in between, as predicted by Na59 and HF86. Bearing in mind the lack of knowledge for the altitudes below $10 \mathrm{~km}$, we conclude that the parameterisation of Brasseur and Chatel (1983) (BC83) is favourable because it reproduces the field data, model data and laboratory measurements reasonably well and includes a detailed temperature and pressure dependence, thus, making it applicable to model calculations and field measurements for any modelled or measured temperature and pressure at any altitude. Therefore, nuances of temperature and pressure variations can be resolved with this 
parameterisation. Furthermore, BC83 also showed the best performance in reproducing the data points of Franchin et al. (2015). For altitudes above $10 \mathrm{~km}$, the parameterisation of Bates (1985) (Ba85) may be used when data of temperature and pressure are lacking; however, this appears to be unlikely for most applications.

\section{Conclusion and outlook}

605 The history of theoretical and empirical approaches to quantify the ion-ion recombination coefficient $\alpha$ and its parameterisations have been reviewed. The parameterisations have been compared to field and laboratory data and to a model calculation of $\alpha$ with a focus on temperature and pressure dependence and their applicability to the troposphere and lower stratosphere, i.e. from 0 to $20 \mathrm{~km}$ altitude. For standard conditions (i.e. $0{ }^{\circ} \mathrm{C}, 1013 \mathrm{hPa}$ ), the value of $1.7 \cdot 10^{-6} \mathrm{~cm}^{3} \mathrm{~s}^{-1}$ is recommended to be used. Evidence is strong that this value is accurate because several authors have derived it independently

610 from laboratory measurements as well as from model calculations. As of today's knowledge, it is the best assumption to use a constant value for altitudes between 0 and $10 \mathrm{~km}$; this is due to the roughly counterbalancing effects of temperature and pressure on the recombination coefficient. Above $10 \mathrm{~km}$, however, a temperature- and pressure-dependent parameterisation must be used to account for the decreasing value of the ion-ion recombination coefficient. The parameterisation of Brasseur and Chatel (1983) shows the best agreement with field and model data and with recent laboratory measurements of $\alpha$. However,

615 the understanding of the processes in ion-ion recombination is far from complete. Binary and ternary recombination mechanisms both play a role, however, their specific temperature and pressure dependencies are not fully resolved up to the present day. The processes that take place inside the "limiting sphere" around the ions are still debated. In addition, the ionion recombination is influenced by the mobilities and masses of the ions. More experiments and state-of-the-art model simulations, including molecular dynamics simulations, are needed to determine the ion-ion recombination coefficient in dependence of temperature, pressure and ion masses and mobilities. This is crucial in order to calculate accurately the recombination loss of ions for the diverse ambient conditions we observe in our atmosphere.

\section{Nomenclature}

a particle (or ion) radius, also named collision radius, in $\mathrm{m}$

$b \quad$ critical collision parameter, in $\mathrm{m}$

$625 d \quad$ radius of the collision sphere around each ion (after Thomson), radius of mutual Coulomb attraction between two ions of opposite charge (after Loeb), also called ion-ion trapping distance (after Natanson), in $\mathrm{m}$

$D$ diffusion coefficient, in $\mathrm{m}^{2} \mathrm{~s}^{-1}$

$D_{+,-} \quad$ diffusion coefficient of the positive, negative ion, in $\mathrm{m}^{2} \mathrm{~s}^{-1}$

$e \quad$ electron charge, $1.602177 \cdot 10^{-19} \mathrm{C}$

$630 E \quad$ external electrical field, in $\mathrm{V} \mathrm{m}^{-1}$ 
$E A \quad$ electron affinity, in $\mathrm{eV}$

$F \quad$ proportionality constant for Hoppel and Frick's theory

$h \quad$ altitude, in $\mathrm{km}$

$k \quad$ number of elementary charges of the aerosol particle

$635 k_{\mathrm{B}} \quad$ Boltzmann constant, $1.380649 \cdot 10^{-23} \mathrm{~J} \mathrm{~K}^{-1}$

$K n_{\delta} \quad$ Knudsen number for the limiting sphere

$L \quad$ loss rate to the electrodes, in $\mathrm{cm}^{-3} \mathrm{~s}^{-1}$

$m \quad$ reduced mass, in $\mathrm{kg}$ (unless noted otherwise)

$M \quad$ molecular mass, in amu

$640[\mathrm{M}] \quad$ number density of air molecules, in $\mathrm{cm}^{-3}$

$n$ number concentration of ions in the gas phase, in $\mathrm{cm}^{-3}$

$n_{-,+} \quad$ number concentration of negative, positive ions in the gas phase, in $\mathrm{cm}^{-3}$

$p \quad$ pressure, in $\mathrm{hPa}$ (unless noted otherwise)

$p_{\delta} \quad$ collision probability for ions entering the limiting sphere

$645 q$ ion pair production rate, in $\mathrm{cm}^{-3} \mathrm{~s}^{-1}$

$r \quad$ distance of the two ions, in $\mathrm{m}$

$r_{0} \quad$ initial distance of the two ions, in $\mathrm{m}$

$R H \quad$ relative humidity, in $\%$

$t \quad$ time, in $\mathrm{s}$

$650 T \quad$ temperature, in $\mathrm{K}$

$v_{+,-} \quad$ mean thermal speed of the positive, negative ion, in $\mathrm{m} \mathrm{s}^{-1}$

$v_{\text {rel }} \quad$ relative thermal speed of two ions of opposite charge, in $\mathrm{m} \mathrm{s}^{-1}$

$w \quad$ function of $x$ (used in Thomson theory)

$x \quad$ function of $d$ and $\lambda$ (used in Thomson theory)

$655 x$ function of $T$ and $p$ (used in Thomson theory)

$\alpha \quad$ ion-ion recombination coefficient, in $\mathrm{cm}^{3} \mathrm{~s}^{-1}$

$\beta^{\mathrm{k}} \quad$ ion-aerosol attachment coefficient, in $\mathrm{cm}^{3} \mathrm{~s}^{-1}$

$\beta_{\delta} \quad$ ion-ion collision rate coefficient at distance $\delta$ (limiting sphere surface)

$\gamma \quad$ function of $a$ or $d$ and $\delta_{\mathrm{F}}$ (used for Fuchs's and Hoppel and Frick's theories)

$660 \Delta \quad$ image capture distance, in $\mathrm{m}$

$\delta \quad$ limiting sphere radius, in $\mathrm{m}$

$\delta$ Hoppel and Frick's limiting sphere radius, in $\mathrm{m}$

$\delta_{3} \quad$ three-body trapping distance, in $\mathrm{m}$

$\delta_{\mathrm{F}} \quad$ Fuchs's limiting sphere radius, in $\mathrm{m}$ 
https://doi.org/10.5194/acp-2021-795

Preprint. Discussion started: 3 November 2021

(c) Author(s) 2021. CC BY 4.0 License.

(c) (i)

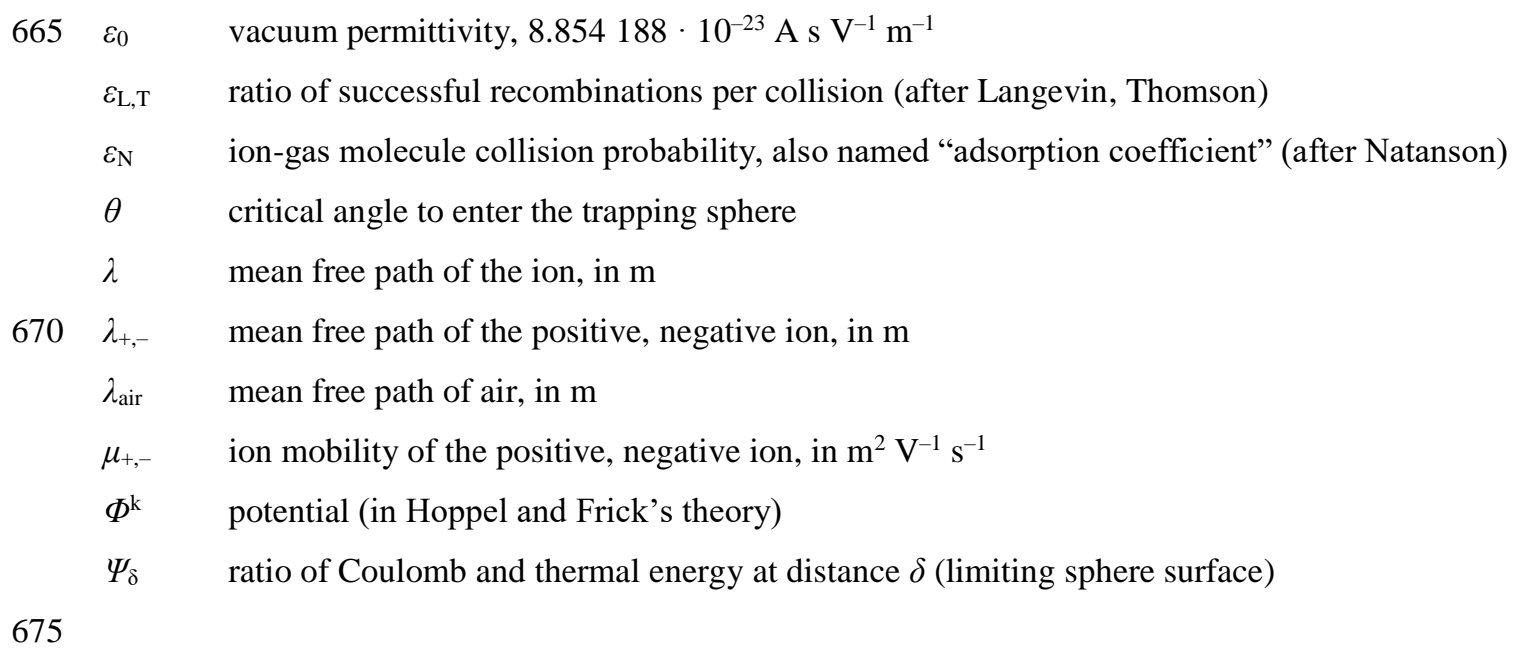

\section{Author contribution}

MZW designed the study, surveyed the literature and compared the parameterisations, models and data sets. MZW and AK modelled the parameterisations and theories. MZW, AK, and JC discussed the results. MZW wrote the manuscript; all coauthors provided input for revision before submission.

\section{Competing interests}

The authors declare that they have no conflict of interest.

\section{Acknowledgements}

$t b w$

\section{Financial support}

685 Marcel Zauner-Wieczorek is funded by the Heinrich Böll Foundation.

\section{References}

Arijs, E.: Positive and negative ions in the stratosphere, Annales Geophysicae, 1, 149-160, 1983. 
Arijs, E., Nevejans, D., Ingels, J., and Frederick, P.: Positive ion composition measurements between 33 and 20 km altitude, Annales Geophysicae, 1, 161-166, 1983.

Arnold, F. and Hauck, G.: Lower stratosphere trace gas detection using aircraft-borne active chemical ionization mass spectrometry, Nature, 315, 307-309, https://doi.org/10.1038/315307a0, 1985.

Arnold, F. and Qiu, S.: Upper stratosphere negative ion composition measurements and inferred trace gas abundances, Planetary and Space Science, 32, 169-177, https://doi.org/10.1016/0032-0633(84)90151-X, 1984.

Arnold, F. and Fabian, R.: First measurements of gas phase sulphuric acid in the stratosphere, Nature, 283, 55-57, https://doi.org/10.1038/283055a0, 1980.

Basu, S., Buchau, J., Rich, F. J., Weber, E. J., Field, E. C., Heckscher, J. L., Kossey, P. A., Lewis, E. A., Dandekar, B. S., McNamara, L. F., Cliver, E. W., Millman, G. H., Aarons, J., Klobuchar, J. A., and Mendillo, M. F.: Chapter 10. Ionospheric radio wave propagation, in: Handbook of geophysics and the space environment, edited by: Jursa, A. S., 1985.

Bates, D. R.: Ion-ion recombination in an ambient gas, Advances in Atomic and Molecular Physics, 20, 1-39, https://doi.org/10.1016/S0065-2199(08)60264-X, 1985.

Bates, D. R.: Recombination of small ions in the troposphere and lower stratosphere, Planetary and Space Science, 30, 12751282, https://doi.org/10.1016/0032-0633(82)90101-5, 1982.

Bazilevskaya, G. A., Usoskin, I. G., Flückiger, E. O., Harrison, R. G., Desorgher, L., Bütikofer, R., Krainev, M. B., Makhmutov, V. S., Stozhkov, Y. I., Svirzhevskaya, A. K., Svirzhevsky, N. S., and Kovaltsov, G. A.: Cosmic Ray Induced Ion Production in the Atmosphere, Space Science Reviews, 137, 149-173, https://doi.org/10.1007/s11214-0089339-y, 2008.

Brasseur, G. and Chatel, A.: Modelling of stratospheric ions: a first attempt, Annales Geophysicae, 1, 173-185, available at: https://orfeo.kbr.be/bitstream/handle/internal/6155/Brasseur\%281983f\%29.pdf?sequence=1\&isAllowed=y, 1983.

Brueckner, K. A.: Ion-Ion Recombination, The Journal of Chemical Physics, 40, 439-444, https://doi.org/10.1063/1.1725134, 1964.

Chapman, S. and Cowling, T. G.: The mathematical theory of non-uniform gases: An account of kinetic theory of viscosity, thermal conduction, and diffusion in gases, 2. ed., 2. repr., Cambridge University Press, Cambridge, 1960.

715 Eisele, F. L. and Hanson, D. R.: First Measurement of Prenucleation Molecular Clusters, J. Phys. Chem. A, 104, 830-836, https://doi.org/10.1021/jp9930651, 2000.

Filippov, A. V.: Charging of Aerool in the Transition Regime, Journal of Aerosol Science, 24, 423-436, https://doi.org/10.1016/0021-8502(93)90029-9, 1993.

Fisk, G. A., Mahan, B. H., and Parks, E. K.: Gaseous Ion Recombination Rates. IV, The Journal of Chemical Physics, 47, 2649-2658, https://doi.org/10.1063/1.1712281, 1967.

Franchin, A., Ehrhart, S., Leppä, J., Nieminen, T., Gagné, S., Schobesberger, S., Wimmer, D., Duplissy, J., Riccobono, F., Dunne, E. M., Rondo, L., Downard, A., Bianchi, F., Kupc, A., Tsagkogeorgas, G., Lehtipalo, K., Manninen, H. E., 
Almeida, J., Amorim, A., Wagner, P. E., Hansel, A., Kirkby, J., Kürten, A., Donahue, N. M., Makhmutov, V., Mathot, S., Metzger, A., Petäjä, T., Schnitzhofer, R., Sipilä, M., Stozhkov, Y., Tomé, A., Kerminen, V.-M., Carslaw, K., Curtius, conditions, Atmospheric Chemistry and Physics, 15, 7203-7216, https://doi.org/10.5194/acp-15-7203-2015, 2015.

Fuchs, N. A.: On the stationary charge distribution on aerosol particles in a bipolar ionic atmosphere, Geofisica pura e applicata, 56, 185-193, https://doi.org/10.1007/BF01993343, 1963.

Gardner, M. E.: The Recombination of Ions in Pure Oxygen as a Function of Pressure and Temperature, Physical Review, 53, 75-83, https://doi.org/10.1103/PhysRev.53.75, 1938.

Gopalakrishnan, R. and Hogan, C. J., J.: Coulomb-influenced collisions in aerosols and dusty plasmas, Physical review. E, Statistical, nonlinear, and soft matter physics, 85, 26410, https://doi.org/10.1103/PhysRevE.85.026410, 2012.

Gringel, W., Käselau, K. H., and Mühleisen, R.: Recombination rates of small ions and their attachment to aerosol particles, Pure and Applied Geophysics, 116, 1101-1113, https://doi.org/10.1007/BF00874674, 1978.

Harrison, R. G.: The global atmospheric electrical circuit and climate, Surveys in Geophysics, 25, 441-484, https://doi.org/10.1007/s10712-004-5439-8, 2004.

Hickman, A. P.: Approximate scaling formula for ion-ion mutual neutralization rates, The Journal of Chemical Physics, 70, 4872-4878, https://doi.org/10.1063/1.437364, 1979.

Hirsikko, A., Nieminen, T., Gagné, S., Lehtipalo, K., Manninen, H. E., Ehn, M., Hõrrak, U., Kerminen, V.-M., Laakso, L., McMurry, P. H., Mirme, A., Mirme, S., Petäjä, T., Tammet, H., Vakkari, V., Vana, M., and Kulmala, M.: Atmospheric ions and nucleation: a review of observations, Atmospheric Chemistry and Physics, 11, 767-798, https://doi.org/10.5194/acp-11-767-2011, 2011.

Hoppel, W. A.: Ion-Aerosol Attachment Coefficients and the Diffusional Charging of Aerosols, in: Electrical Processes in Atmospheres: proceedings of the 5. Internat. Conference on Atmospheric Electricity held at Garmisch-Partenkirchen (Germany), 2 - 7 September 1974, edited by: Dolazek, H. and Reiter, R., Steinkopff, Darmstadt, 60-69, 1977.

Hoppel, W. A. and Frick, G. M.: Ion-Aerosol Attachment Coefficients and the Steady-State Charge Distribution on Aerosols in a Bipolar Ion Environment, Aerosol Science and Technology, 5, 1-21, https://doi.org/10.1080/02786828608959073, 1986.

Israël, H.: Atmospheric Electricity: Volume I. Fundamentals, Conductivity, Ions, 2nd ed., Israel Program for Scientific Translations Ltd, Jerusalem, 1971.

Israël, H.: Atmosphärische Elektrizität: Teil 1. Grundlagen, Leitfähigkeit, Ionen, Akademische Verlagsgesellschaft Geest \& Portig K.G., Leipzig, 1957.

Keefe, D., Nolan, P. J., and Scott, J. A.: Influence of Coulomb and Image Forces on Combination in Aerosols, Proceedings of the Royal Irish Academy. Section A: Mathematical and Physical Science, 66, 17-29, available at: https://www.jstor.org/stable/20488658, 1968.

Langevin, M. P.: Recombinaison et mobilités des ions dans les gaz, Annales de chimie et de physique, 433-530, 1903a. 
Langevin, M. P.: Sur la loi de recombinaison des ions, Comptes rendus hebdomadaires des séances de l'Académie des sciences, 177-179, 1903b.

Lee, H. S. and Johnsen, R.: Ion-ion recombination studies in ambient helium and argon at atmospheric densities, The Journal of Chemical Physics, 90, 6328-6334, https://doi.org/10.1063/1.456349, 1989.

Lenz, E.: Die Wiedervereinigung von Ionen in Luft bei niederen Drucken, Zeitschrift für Physik (Zschr. f. Physik), 76, 660678, https://doi.org/10.1007/BF01341939, 1932.

Loeb, L. B.: Basic Processes of Gaseous Electronics, Second edition, revised, University of California Press and Cambridge University Press, Berkeley, Los Angeles and London, 1960.

Loeb, L. B.: Basic Processes of Gaseous Electronics, University of California Press, Berkeley, 1955.

Loeb, L. B. and Marshall, L. C.: The Theory of Recombination of Gaseous Ions, Journal of the Franklin Institute, 208, 371388, https://doi.org/10.1016/S0016-0032(29)91182-0, 1929.

López-Yglesias, X. and Flagan, R. C.: Ion-Aerosol Flux Coefficients and the Steady-State Charge Distribution of Aerosols in a Bipolar Ion Environment, Aerosol Science and Technology, 47, 688-704, https://doi.org/10.1080/02786826.2013.783684, 2013.

Miller, T. M.: Parametrization of ion-ion mutual neutralization rate coefficients, The Journal of Chemical Physics, 72, 46594660, https://doi.org/10.1063/1.439711, 1980.

Miller, T. M., Friedman, J. F., and Viggiano, A. A.: A new technique for studying ion-ion recombination in a flowing afterglow Langmuir probe apparatus: Ar+ recombining with $\mathrm{Cl} 2-, \mathrm{CCl} 2 \mathrm{O}-, \mathrm{Br} 2-, \mathrm{SF} 5-$ and $\mathrm{SF} 6-$, International Journal of Mass Spectrometry, 267, 190-198, https://doi.org/10.1016/j.ijms.2007.02.033, 2007.

Morita, Y.: Recent measurements of electrical conductivity and ion pair production rate, and the ion-ion recombination coefficient derived from them in the lower stratosphere, Journal of Geomagnetism and Geoelectricity, 35, 29-38, https://doi.org/10.5636/jgg.35.29, 1983.

Natanson, G. L.: On the Theory of the Charging of Amicroscopic Aerosol Particles as a Result of Capture if Gas Ions, Journal of Technical Physics, 5, 538-551, 1960a.

Natanson, G. L.: On the Theory of the Charging of Amicroscopic Aerosol Particles as a Result of Capture if Gas Ions, Zhurnal Tekhnicheskoi Fiziki, 30, 573-588, 1960b.

Natanson, G. L.: The Theory of Volume Recombination of Ions, Journal of Technical Physics, 4, 1263-1269, 1959a.

Natanson, G. L.: The Theory of Volume Recombination of Ions, Zhurnal Tekhnicheskoi Fiziki, 29, 1373-1380, 1959b.

785 National Oceanic and Atmospheric Administration, National Aeronautics and Space Administration, and United States Air Force: U.S. Standard Atmosphere, 1976, U.S. Government Printing Office, Washington, D.C., 1976.

Nolan, P. J.: The Recombination Law for Weak Ionisation, Proceedings of the Royal Irish Academy. Section A: Mathematical and Physical Science, 49, 67-90, available at: https://www.jstor.org/stable/20488452, 1943.

Rosen, J. M. and Hofmann, D. J.: Balloon-borne measurements of electrical conductivity, mobility, and the recombination coefficient, Journal of Geophysical Research: Oceans, 86, 7406-7410, https://doi.org/10.1029/JC086iC08p07406, 1981. 
https://doi.org/10.5194/acp-2021-795

Preprint. Discussion started: 3 November 2021

(C) Author(s) 2021. CC BY 4.0 License.

(c) (i)
Atmospheric

Chemistry

and Physics

Discussions

Sagalyn, R. C., Burke, H. C., and Fitzgerald, D. R.: Chapter 20. Atmospheric electricity, in: Handbook of geophysics and the space environment, edited by: Jursa, A. S., 1985.

Sayers, J.: Ionic recombination in air, Proc. R. Soc. Lond. A, 169, 83-101, https://doi.org/10.1098/rspa.1938.0196, 1938.

Smith, D. and Adams, N. G.: Ionic recombination in the stratosphere, Geophys. Res. Lett., 9, 1085-1087, https://doi.org/10.1029/GL009i009p01085, 1982.

Smith, D. and Church, M. J.: Ion-ion recombination rates in the earth's atmosphere, Planetary and Space Science, 25, 433439, https://doi.org/10.1016/0032-0633(77)90075-7, 1977.

Tamadate, T., Higashi, H., Seto, T., and Hogan, C. J., J.: Calculation of the ion-ion recombination rate coefficient via a hybrid continuum-molecular dynamics approach, The Journal of Chemical Physics, 152, 94306, https://doi.org/10.1063/1.5144772, 2020.

Tang, M. J., Cox, R. A., and Kalberer, M.: Compilation and evaluation of gas phase diffusion coefficients of reactive trace gases in the atmosphere: volume 1. Inorganic compounds, Atmospheric Chemistry and Physics, 14, 9233-9247, https://doi.org/10.5194/acp-14-9233-2014, 2014.

Thirkill, H.: On the recombination of the ions produced by Röntgen rays in gases and vapours, Proc. R. Soc. Lond. A, 88, 477-494, https://doi.org/10.1098/rspa.1913.0046, 1913.

Thomson, J. J.: XXIX. Recombination of gaseous ions, the chemical combination of gases, and monomolecular reactions, The London, Edinburgh, and Dublin Philosophical Magazine and Journal of Science, 47, 337-378, https://doi.org/10.1080/14786442408634372, 1924.

Thomson, J. J. and Rutherford, E.: XL. On the passage of electricity through gases exposed to Röntgen rays, The London, Edinburgh, and Dublin Philosophical Magazine and Journal of Science, 42, 392-407, https://doi.org/10.1080/14786449608620932, 1896.

Viggiano, A. A. and Arnold, F.: Ion Chemistry and Composition of the Atmosphere, in: Handbook of Atmospheric Dynamics. Volume 1. Atmospheric Electricity, edited by: Volland, H., CRC Press, Boca Raton, London, Tokyo, 1-25, 1995.

815 Wright, P. G.: On the Discontinuity Involved in Diffusion Across an Interface (The $\Delta$ of Fuchs), Discussions of the Faraday Society, 30, 100-112, https://doi.org/10.1039/df9603000100, 1960. 